\title{
The Rhizobium meliloti groELc locus is required for regulation of early nod genes by the transcription activator NodD
}

\author{
Joy Ogawa and Sharon R. Long ${ }^{1}$ \\ Howard Hughes Medical Institute, Department of Biological Sciences, Stanford University, \\ Stanford, California 94305-5020 USA
}

\begin{abstract}
The molecular chaperones related to GroEL (hsp60, cpn60) interact with partially folded proteins and appear to assist them to attain active and correctly folded conformation. They are required for cell viability but are probably more important for some processes than for others. Through a random genetic search to find loci that are required for expression of the Rhizobium meliloti nod (nodulation) genes, we isolated a mutant (B4) defective in luteolin-dependent activation of nod gene expression, and found it carries a Tn5 insertion within a chromosomal groEL gene (groELc) located just downstream of a groESc gene. The groELc mutation affected activity of three related LysR-type activator proteins NodD1, NodD3, and SyrM; on plants, the mutants formed nodules late, and the nodules were $\mathrm{Fix}^{-}$. Hybridization and protein expression analysis show that a similar groESL locus (groESLa) maps to the Rm1021 megaplasmid pSyma. Southern blot analysis revealed additional, but less closely related sequences hybridizing to groELc and groESc probes elsewhere in the $R$. meliloti genome. Clones of groESLc and groESLa can each restore robust phage $\lambda$ growth on an Escherichia coli groE mutant. Likewise each clone can complement all of the phenotypes observed for B4 mutants; thus, the two appear to be functionally equivalent if expression is controlled. We determined that groELc is required for normal DNA binding of the NodD target sequence in $R$. meliloti. GroEL coimmunopurifies with NodD1 from $R$. meliloti, which suggests a direct physical association between these proteins. GroEL is thus probably involved in the folding or assembly of transcriptionally active NodD.
\end{abstract}

[Key Words: Rhizobium meliloti; GroEL; nod genes; NodD; LysR; sym plasmid; transcriptional activation]

Received November 1, 1994; revised version accepted February 15, 1995.

Rhizobium meliloti is a Gram-negative bacterium that can either live as a soil scavenger, or can invade specific host plants including alfalfa (Medicago sativa) to initiate a symbiosis. The symbiotic process begins when the bacteria stimulate the plants to begin the development of root nodules (Long 1989). Rhizobium cells trigger nodule development by the action of their nodulation (nod) genes, which appear to encode enzymes that synthesize a family of morphogens active on plants (Fisher and Long 1992; Dénarié and Cullimore 1993; Downie 1994; Geiger et al. 1994). The nod genes are located on a large (1400-1500 kb) plasmid termed pSyma; a second, larger $(1700 \mathrm{~kb})$ plasmid, pSymb, contains other genes for symbiosis including those for synthesis of exopolysaccharide (Charles and Finan 1991).

The correct expression of the early-acting $R$. meliloti nod genes requires induction from the host plant (for review, see Fisher and Long 1992; Kondorosi 1992). We found that alfalfa seeds secrete a flavonoid, luteolin, that induces Rhizobium nod gene expression by a mechanism requiring an activator gene, nodD (Mulligan and

\footnotetext{
${ }^{1}$ Corresponding author.
}

Long 1985; Peters et al. 1986). NodD is a member of the LysR family of prokaryotic transcription activator proteins (Henikoff et al. 1988; for review, see Schell 1993). The LysR proteins are typically $30-35 \mathrm{kD}$, and often are transcribed divergently from an operon that they regulate. Some have both repressor and activator functions. Their molecular basis for action is not known.

Different Rhizobium strains have NodD proteins that function in common to activate expression of nod genes but do so in response to inducers that vary according to the host plant (for review, see Fisher and Long 1992; Kondorosi 1992; Schlaman et al. 1992). R. meliloti has three nodD genes: nodD1 is constitutively expressed (Mulligan and Long 1985), and the protein product NodD1 activates nod operons in the presence of luteolin, 4,4'-hydroxy-6-methoxy chalcone (HMC) and related compounds; nodD2 requires compounds other than luteolin, including HMC and betaines such as trigonelline (for review, see Phillips 1992). nodD3 encodes a protein, NodD3, that is capable of transcriptional activation without any plant inducer (Mulligan and Long 1989; Swanson et al. 1993). However, the expression of this locus is itself under complex control, so that there is little NodD3 protein present in cultured Rhizobium, and 
it is expressed later in the symbiosis under the control of syrM, another LysR-type activator (Barnett and Long 1990; for review, see Kondorosi 1992).

The action of NodD proteins has been studied by genetic and biochemical approaches. nod promoters are characterized by the presence of a nod box. NodD binds to the nod box (for review, see Kondorosi 1992), establishing a footprint of up to $55 \mathrm{bp}$, and bends the DNA at the nod box (Fisher and Long 1993). The presence of inducer is not necessary for DNA binding by purified NodD protein, and the exact biochemical role of inducer in transcription activation is not understood.

Some bacteria transduce external signals into gene expression by way of a two-component modular response regulatory system (for review, see Parkinson 1993). In the simplest cases, the regulatory properties of a DNAbinding protein (such as FixJ, CheY, DctD) are controlled by a partner histidine kinase (FixL, CheA, DctB), which senses an internal or external condition. We asked whether NodD required a comparable partner to respond to inducer, and searched genetically for such a partner by mutagenesis and screening. What we found instead was a locus that is necessary for the activity of NodD and SyrM, independent of inducer requirements. Analysis of this locus showed that it is a Rhizobium homolog of the Escherichia coli GroEL protein (hsp60, chaperonin-60), a molecular chaperone required for correct folding of some proteins, and for allowing their correct assembly with other polypeptides (Ellis and van der Vies 1991; Georgeopoulos 1992; Hendrick and Hartl 1993). We established that GroEL affects the ability of NodD to bind promoters normally and that $R$. meliloti GroEL associates biochemically with the NodD activator protein. This is a novel direct genetic discovery in a homologous system of a role for GroEL in transcription activation. $R$. meliloti at least has two fully functional copies of groESL, and a chromosomal one is required for activation of nod genes through NodD; a second, borne on the sym plasmid pSyma, appears sufficient for all other growth functions.

\section{Results}

\section{A R. meliloti Tn5 mutant displays altered nod gene expression}

To investigate how $R$. meliloti NodD acts with plant inducers to cause activation of nod gene promoters, we asked whether other genetic loci were required for correct induction by luteolin, the inducer isolated from alfalfa seeds (Peters et al. 1986). We examined nine mutants generated by $\mathrm{Tn} 5$ mutagenesis of $R$. meliloti strain ALl10, which carries a nodC'-'lacZ fusion. One mutant, designated $B 4$, displayed reduced $(\sim 14-25 \%$ of normal) luteolin-mediated nod $C^{\prime}-1 a c Z$ expression, and this behavior was still displayed when extra copies of nodD1, nod $A B C^{\prime}-'$ lacZ were provided in trans (Table 1). NodA protein levels, as detected by antibody, were also markedly lower in a B4 mutant background (data not shown), confirming a direct and general effect of B4 on nod gene
Table 1. Effect of B4 mutation on nod gene induction

\begin{tabular}{llcc}
\hline & & \multicolumn{2}{c}{$\begin{array}{c}\text { Units } \beta \text {-galactosidase } \\
\text { (fold induction) }\end{array}$} \\
\cline { 3 - 4 } Strain & $\begin{array}{l}\text { Plasmid } \\
\text { (description) }\end{array}$ & - luteolin & +luteolin \\
\hline AL110 & none & 0.5 & $8.1(16 \times)$ \\
B4 & none & 0.4 & $2.1(5 \times)$ \\
AL110 & pO57.33 (nodD1 & 22 & $640(29 \times)$ \\
& nodABC'-'lacZ) & & \\
B4 & pO57.33 & 13 & $51(4 \times)$ \\
\hline
\end{tabular}

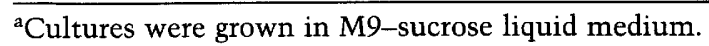

expression. Linkage of $\operatorname{Tn} 5$ to the phenotype was shown by phage $\mathrm{N} 3$ transduction.

Several lines of evidence indicated that the effect of the B4 mutant was on NodD activity, not on its expression or on the effect of luteolin. First, we found that expression of nodD1 was not reduced (Table 2, lines 1,2). Western blots probed with anti-NodD antibodies showed that NodD1 is present in B4T3 (pO57.33) at a lower level than that found in AL110 (pO57.33) (data not shown); however, the less than twofold difference in protein level could not account for the approximately sevenfold decrease in NodD function inferred from Table 1.

Second, we tested whether the B4 mutation affected cell reaction to inducer (luteolin) or whether it affected NodD action independent of inducer. We exploited the multigene nodD family of $R$. meliloti: One of the copies, nodD3, encodes an inducer-independent activator protein (Mulligan and Long 1989; Maillet et al. 1990; Kondorosi et al. 1991; Swanson et al. 1993). Expression of nodD 3 is normally low and is controlled by $\operatorname{syr} M$, which, like nodD, encodes a member of the LysR protein activator family (Barnett and Long 1990; Kondorosi et al. 1991). We circumvented the requirement for syrM by using a plasmid (pE65) on which nodD3 is expressed from a trp promoter (Egelhoff and Long 1985; Fisher et al. 1988). The presence of the B4 mutation significantly decreased nod $C^{\prime}-1 a c Z$ expression (Table 2, cf. lines 3 and 4). This supported the hypothesis that the product of the B4 locus was required for NodD function, whether NodD1 or NodD3, not for transducing the effect of the plant-derived inducer.

Examining the more complex effects of syrM and nodD3 combined suggested that SyrM activity itself is also affected by the B4 mutation. When both syrM and nodD 3 are expressed in trans on plasmid pJT5, nod $C^{\prime}-$ 'lacZ gene expression is high in wild-type cells (Table 2, line 5). This effect was drastically reduced in the B4 mutant background (line 6). We tested for nodD 3 expression by means of three independent nodD3-lacZ or nodD3gusA transcriptional fusions (Table 2, lines 7 and 8 ; data not shown). We found that nodD3expression was sensitive to the B4 mutant background. As syrM expression was not decreased (Table 2, lines 9 and 10), it is possible that SyrM protein loses its ability to activate nodD3 expression in the B4 background.

We used antibody to examine the relationship of 
Table 2. Effect of B4 mutation on nodD expression and NodD activity

\begin{tabular}{|c|c|c|c|}
\hline \multirow{2}{*}{$\begin{array}{l}\text { Strain } \\
\text { (description) }\end{array}$} & \multirow{2}{*}{$\begin{array}{l}\text { Plasmid } \\
\text { (description) }\end{array}$} & \multicolumn{2}{|c|}{ Enzyme activity ${ }^{a}$} \\
\hline & & - luteolin & +luteolin \\
\hline & & \multicolumn{2}{|c|}{ units $\beta$-galactosidase } \\
\hline 1. $\mathrm{Rml021}$ & pM61 (nodD1'-'lacZ) & 510 & 500 \\
\hline 2. $\mathrm{B} 4 \mathrm{Tl}$ & pM61 & 620 & 620 \\
\hline 3. $\mathrm{AL} 110\left(\operatorname{nod} A B C^{\prime}-{ }^{\prime} l a c Z\right)$ & pE65 $(\text { Ptrp } \rightarrow \text { nodD3 })^{\mathrm{b}}$ & 490 & 480 \\
\hline 4. $\mathrm{B} 4 \mathrm{~T} 3\left(\operatorname{nod} A B C^{\prime}-{ }^{\prime} l a c Z\right)$ & pE65 & 59 & 70 \\
\hline 5. AL110 & pIT5 (syrM, nodD3, . . .) & 250 & 270 \\
\hline 6. B4T3 & pIT5 & 3 & 5 \\
\hline 7. JAS301 (nodD3-lacZ 5-1 fusion) & pJT5 & 54 & 52 \\
\hline \multirow[t]{2}{*}{ 8. B4Sp2 nodD3-lacZ 5-1 fusion } & pIT5 & 4 & 3 \\
\hline & & \multicolumn{2}{|c|}{ units $\beta$-glucuronidase $\times 10^{3}$} \\
\hline 9. AL110 & pM142 (syrM-gusA fusion) & 330 & 360 \\
\hline 10. B4T3 & pMl42 & 650 & 660 \\
\hline
\end{tabular}

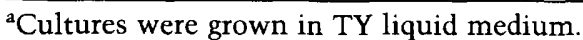

${ }^{b}$ To confirm the validity of the expression vector, we tested the activity of the trp promoter with plasmid pF644 [R.F. Fisher (this laboratory), unpub.] and found that the same trp promoter drove similar levels of lazZ expression in the B4 background and in wild-type Rm1021 (data not shown).

NodD3 protein level to the inferred activity on downstream gene expression (data not shown). When nodD3 is expressed from the trp promoter in the B4 mutant background (represented in Table 2, line 4), the level of NodD3 protein was decreased but not enough to account for the activity decrease. Moreover, this B4 strain containing trp-driven nodD3 (Table 2, line 4) has about twice the level of NodD3 protein detected in AL110 (pJT5) (represented in Table 2, line 5), and yet the latter strain showed much higher NodD3-dependent nod $C^{\prime}-$ 'lacZ expression. Overall, we conclude that the B4 mutation affects both the expression of nodD 3 and the activity of the NodD3 that does get expressed.

\section{Free-living and symbiotic phenotypes of the B4 mutant}

Strain B4T1 (the Tn5 from B4 transduced into a wildtype Rm1021 background) grew slightly slower than wild type on both solid and liquid medium, either rich or minimal (e.g., $25 \%$ longer doubling time than wild type in TY liquid medium). Otherwise, we observed no effects of the mutation on growth of cultured cells. B4 mutants supported growth of phage N3, allowing transduction of markers between strains. B4 mutant colonies fluoresced under UV light when grown on Calcofluor-containing medium, indicating the normal presence of succinoglycan (Leigh et al. 1985). Colony morphology was normal. However, the mucoid phenotype caused by multicopy syrM (Mulligan and Long 1989) was not seen in a B4 background (data not shown). This phenotype was consistent with the parallel loss of SyrM-dependent nodD3 expression.

B4 mutants showed two levels of symbiotic defect: (1) B4T1-induced nodules formed 4-9 days later than wild type, and fewer plants became nodulated $(40-60 \%$, compared to almost $100 \%$ of plants nodulated by wild type after 22 days); and (2) B4T1-induced nodules failed to fix nitrogen $\left(\mathrm{Fix}^{-}\right)$, resulting in stunted and chlorotic plants with white or gray nodules instead of the usual pink nodules formed by Rm1021. As judged by acetylene reduction assays, B4Tl-induced nodules showed $<1 \%$ of the nitrogen-fixing activity of wild-type Rm1021-induced nodules: $20-70$ nmoles of ethylene were produced in $8 \mathrm{hr}$ per B4Tl-nodulated plant, $\sim 10$-fold over background, compared with $7000-10,000$ nmoles for wildtype-nodulated plants. Uninoculated plants or plants inoculated with a nif $A:: \operatorname{Tn} 5$ strain did not generate detectable levels of ethylene.

We suspected that the $\mathrm{Fix}^{-}$phenotype of the $\mathrm{B} 4 \mathrm{mu}-$ tants was not attributable to nod gene expression defects, because although nodD mutants form nodules late and in low number, these nodules are usually $\mathrm{Fix}^{+}$once they form (Jacobs et al. 1985). We tested for whether the Fix ${ }^{-}$phenotype correlated with reduced NifA-dependent activation of nif-gene expression. However, nif expression was not reduced. First, nif $A$-dependent activation of $n i f H D K$ expression was similar in wild type and in B4, as measured by a nifH'-'gusA fusion on a plasmid in these strains (Sharma and Signer 1990) cultured under microaerobic conditions that normally lead to activation of nif $A$ expression and consequently to activation of nifHDK expression (Ditta et al. 1987; David et al. 1988) (data not shown). Second, expression of a nif $A^{\prime}-{ }^{\prime} l a c Z$ fusion on pCHK57 (Ditta et al. 1987) was comparable in mutant B4 and in Rm1021, grown under aerobic or microaerobic conditions. Thus, reduction of nifA-dependent activation of nif-gene expression is probably not the basis for the Fix ${ }^{-}$phenotype of the B4 mutant, and direct effects on nitrogen fixation seem more likely (see Discussion).

\section{The B4 Tn5 disrupts a groEL gene}

We mapped the $\mathrm{Tn} 5$ in the B4 mutant to the chromosome of $R$. meliloti, first by showing that the Tn 5 resis- 
tance did not cotransfer with either pSym (Finan et al. 1986), and subsequently by conjugation analysis (Glazebrook et al. 1992; Klein et al. 1992), finding that the B4 mutation lies between fix-382 and ura-501 (Fig. 1A). The mutation failed to show transductional linkage to loci mapped previously (pho-1, fix-382, $\operatorname{deg} P$ ).

We cloned the Tn5-containing region of mutant $\mathrm{B} 4$ on a ClaI fragment to produce pJO91 (Fig. 2A). Internal 1.6$\mathrm{kb}$ Xhol fragment and 5.3-kb BamHI fragment probes (X and $\mathrm{Y}$ in Fig. 2A/ consistently hybridized to two fragments of Rm1021 genomic DNA digested with enzymes that did not cut within the cloned $R$. meliloti sequence contained in pJO91 (data not shown; also, two nonidentical sets of much fainter bands also appeared on blots hybridized with probe $\mathrm{X}$ or probe $\mathrm{Y}$ ). We concluded that there were at least two loci in the $R$. meliloti genome with DNA corresponding to the $\mathrm{B} 4$ open reading frame. We cloned strongly hybridizing 7.9- and 12-kb BglII fragments to yield a series of $\lambda$ clones and the plasmids pJO101 and pJO32, respectively. We confirmed that in the B4 mutant, Tn5 is inserted into the sequence corresponding to the 7.9-kb BgIII band.

The DNA sequence for pJO101 (GenBank accession number U19726) showed that it contains a 1635 base open-reading-frame (ORF) encoding a $57.7-\mathrm{kD}$ polypeptide that bears a striking similarity to $E$. coli GroEL and other chaperonin-60 proteins (Ogawa 1993; data not shown). In mutant B4, the Tn5 interrupts this ORF about one-fifth of the way in from the 5 '-end, after nucleotide 350 of the groEL ORF. Just upstream of the groEL-like sequence is a 294-base ORF encoding a 10.6-kD polypeptide that is similar to $E$. coli GroES and other chaperonin-10 proteins.

\section{The second copy of the R. meliloti groESL is located on $p$ Syma}

The second B4-homologous locus (pJO32) lay on a 2.9-kb $\mathrm{XbaI}$ fragment, in a segment with a restriction map identical to the corresponding region of the pJO101 clone (Fig. 2). Preliminary DNA sequence was completely identical for at least $200 \mathrm{bp}$ surrounding the SmaI site of pJO32 and pJO101. Using R. meliloti S-30 extracts (Fisher et al. 1987), we found by coupled transcriptiontranslation reactions that both clones encode a protein migrating at $60 \mathrm{kD}$ (Fig. 3, lanes 5-10, top arrow), comparable to the upper band of the E. coli GroEL doublet (lanes 3,4). Another band migrating at $13 \mathrm{kD}$ (bottom arrow) corresponded to cloned $R$. meliloti groES genes. This band migrates faster than E. coli GroES (lanes 3,4, open arrowhead), which displays an apparent mobility corresponding to $15 \mathrm{kD}$ (Tilly et al. 1981), although its molecular size is inferred from DNA sequence to be 10 $\mathrm{kD}$ (Hemmingsen et al. 1988). The presence of the 60and $13-\mathrm{kD}$ bands in all reactions with plasmid containing cloned Rm1021 DNA, regardless of orientation, suggests the presence of active $R$. meliloti promoters on the cloned fragments.

The protein and partial sequence data of pJO32 suggested the existence of a second groESL locus. We showed that this was located on pSyma by probing DNA of megaplasmid-containing derivatives of Agrobacterium tumefaciens strain Al36 (Fig. 1C). We further defined the location by analyzing $R$. meliloti strains with known deletions in pSyma: Analysis with Southern blots of restricted DNA revealed that the 12-kb BgIII fragment was present in deletion GMI255 (Fig. 1C) but absent from GMI766 (Fig. 1D: cf. lane 3 with 6, and lane 9 with 12). Therefore, these genes are located within a region extending at least $70 \mathrm{~kb}$ from nifHDK, distal to the common nod genes (Truchet et al. 1985) (Fig. 1B). We have named the pSyma located genes groESLa; the chromosomal genes mutated in $\mathrm{B} 4$ have been designated groESLC.

Other related sequences are present in the R. meliloti genome: Hybridizations of Southern blots with small probes internal to the groELc ORF revealed two to three additional bands (Fig. 1D, lanes 7-9). However, fewer, and different, genomic fragments hybridized to the groESc ORF compared with those hybridizing to the groELc probe (lanes 1-3 vs lanes $7-9$ ). We conclude that there are at least three additional copies of groEL-like sequences in the Rm1021 genome and at least two additional copies of groES-like sequences. Only one pair of the additional groESand groEL copies are clearly linked to each other in the Rm1021 genome, but these hybridize only faintly to probes made from the pJO101 clone; if the other additional groES-like and groEL-like copies are paired in operons, they do not share the same internal restriction pattern as the copies cloned in pJO32 and pJO101. In work to be published elsewhere (J. Ogawa and S.R. Long, in prep.l, we have demonstrated that the presence of either groELC or of groELa is required to sustain cell viability. The function, if any, of the other hybridizing bands is not known.

Recently, Rusanganwa and Gupta (1993) reported the cloning of three groEL-like genes from $R$. meliloti Rm1021, which they obtained using a probe generated by polymerase chain reaction using degenerate oligonucleotide primers, and they reported that hybridizing bands were present on both pSyma and pSymb. Based on their reported restriction map and DNA sequence, we conclude that their clone RhzA corresponds to groELc. Our DNA sequence of groELc is nearly identical to the reported sequence of RhzA within the coding region. Outside of the coding region, there are several discrepancies between the two sequences; however, we think that these discrepancies are probably attributable to technical differences in the determination of the DNA sequence, and not the result of our having sequenced a different gene. One of the other two groEL-like clones described by Rusanganwa and Gupta (1993) is preceded by a groES-like sequence and the other is not; neither of these clones correspond to groELa or groELc.

Functional comparison of E. coli groESL, groESLc, and groESLa

We tested function of broad host-range clones carrying the $R$. meliloti groESLa and groESLc and the E. coli 
Ogawa and Long

A

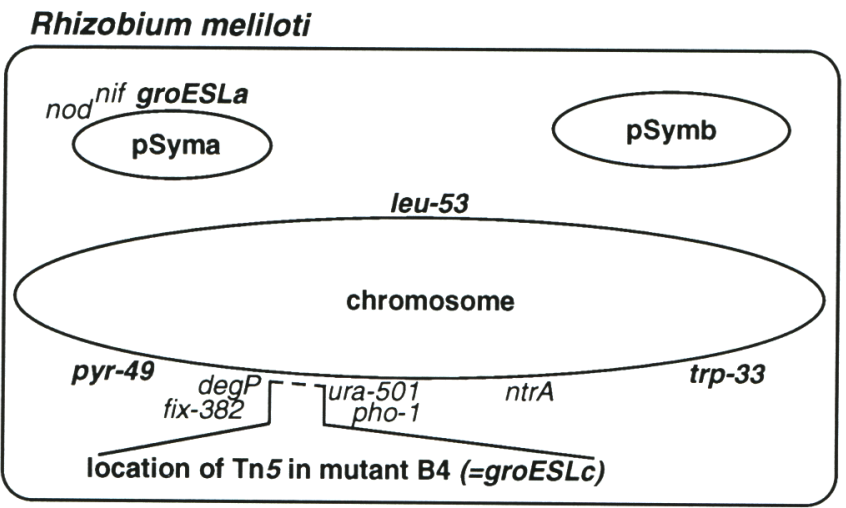

B

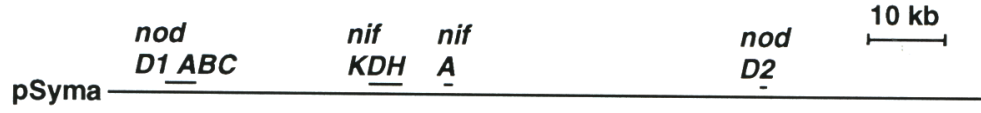

deleted in

deleted in GMI766

D

probe S

probe L2

C
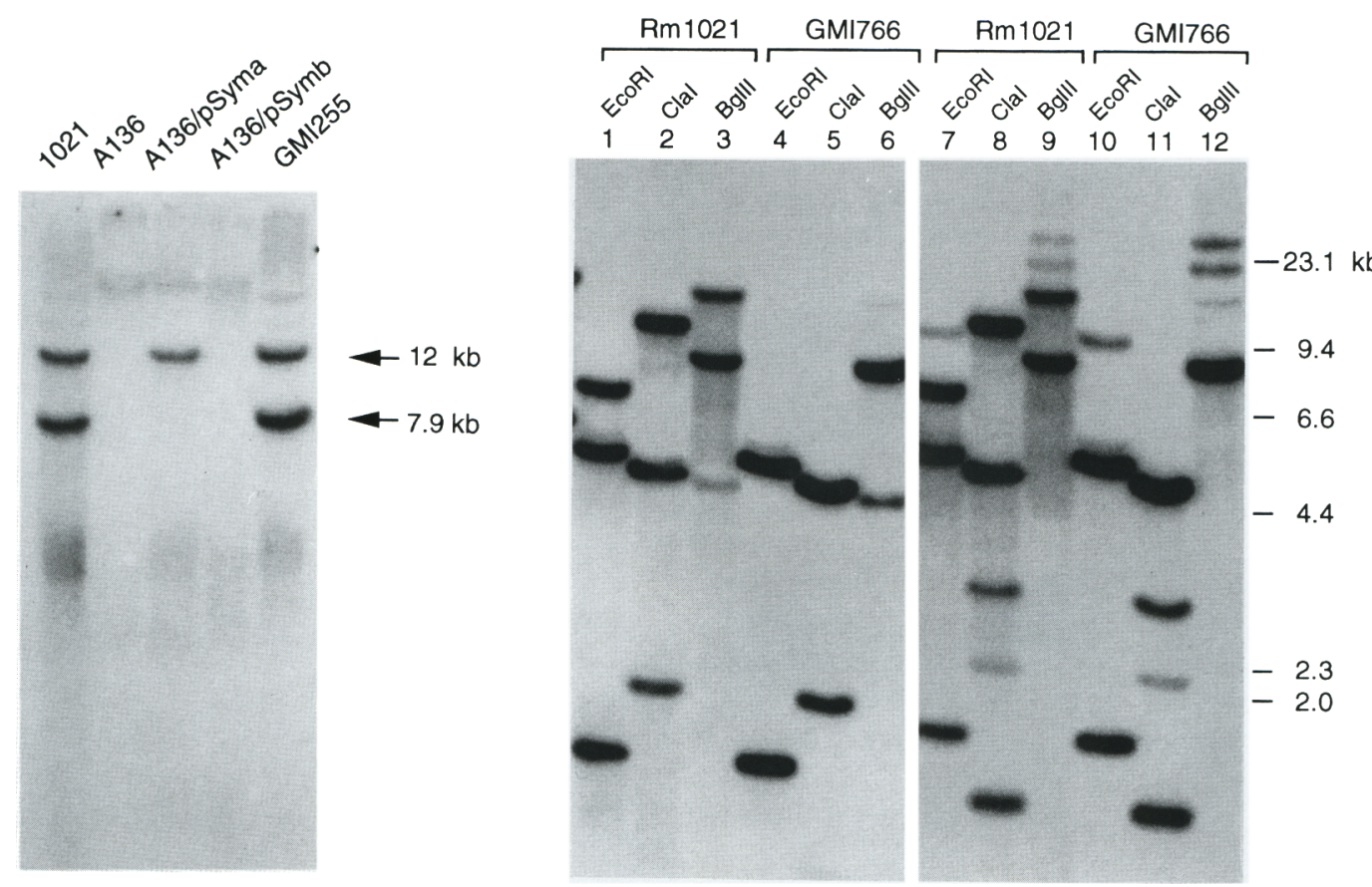

Figure 1. (See facing page for legend.)

groESLgenes. The $R$. meliloti clones restored wild-type growth to $\mathrm{B} 4$ derivatives. Also, the groESLC and groESLa clones both restore B4T3 luteolin-induced $\beta$-galactosidase activity to wild-type levels (Table 3). However, this 
was not an exclusive property of the $R$. meliloti cloned genes: The E. coli groESL clone (pO43) increased luteolin-induced nodC-lacZ expression fourfold over wild type. The quantitative effect of the $E$. coli clone could be attributable at least in part to the high levels of expression supported by the $E$. coli groESL promoter seen in coupled transcription-translation reactions using $R$. meliloti S-30 extracts (Fig. 3, lanes 3,4), although it is possible that there are also functional differences between the E. coli and R. meliloti GroEL proteins.

We tested for complementation of the two other symbiotic defects, delayed nodulation and $\mathrm{Fix}^{-}$nodules, by introducing the groESL clones into $\mathrm{B} 4 \mathrm{Tl}$ and into a wildtype control; in each case, a parallel recA::Tn5-233 derivative was also tested (data not shown; Ogawa 1993). The two $R$. meliloti clones successfully complemented both nodulation and nitrogen fixation phenotypes. Adding extra copies of groESLa or groESLc did not affect nodulation kinetics or $\mathrm{Fix}^{+}$phenotype of the wild-type control. A modest decrease in overall vigor of the $\mathrm{Rec}^{-}$ strains was evident in all cases but did not affect the conclusions: Clones of both groESLc and groESLa restored symbiotic phenotype to wild-type levels.

On the other hand, the E. coli groESL clone pO43 did not complement nodulation delay or the Fix ${ }^{-}$phenotype of the B4 Tn5-insertion mutants. The apparent lack of function is probably attributable in part to plasmid instability: We observed a high frequency of loss of the $E$. coli groESL plasmid during nodulation (data not shown). Functional differences of the $E$. coli cloned groESL are nonetheless possible, as suggested by its failure to complement the slow growth in culture of B4 derivatives (data not shown).

We also tested the converse situation, asking whether the $R$. meliloti groESL genes would complement $E$. coli strains carrying mutations in groES and groEL, which fail to support $\lambda$ growth and are temperature sensitive for growth at $43^{\circ} \mathrm{C}$ (Tilly and Georgeopoulos 1982). As shown in Table 4, pBluescript-based groESLC and groESLa clones were comparable to the E. coli groESL clones in ability to complement $E$. coli groES and groEL mutants for ability to support $\lambda$ growth. These clones were less effective at complementing the temperaturesensitive growth phenotype, in that colonies formed but they were very small. It is possible that $R$. meliloti GroEL does not function well at $43^{\circ} \mathrm{C}$, because $R$. meliloti 1021 does not itself grow on LB agar at $43^{\circ} \mathrm{C}$. We noted that when $E$. coli groESL were cloned into pBluescript SK + such that these genes were in the same orientation as the lac promoter, the resulting clone did a very poor job of complementing the mutants, whereas cloning these genes such that the groESLgenes are transcribed opposite the lac promoter resulted in a clone that was very proficient at complementing the groES and groEL mutants. A lower copy number version of the $R$. meliloti groESLc, cloned downstream of the lac promoter in a pACYC184-based vector, was not as effective at complementing either of the phenotypes of the $E$. coli groE mutants (data not shown; see Table 5).

\section{NodD-DNA binding requires GroEL}

Cell-free extracts of B4T3 carrying the nodD3-over-expressing clone pE65 were tested in the gel-mobility shift assay side by side with extracts of AL110 (pE65) (Fig. 4A). The nodA promoter-specific DNA-binding activity seen in an extract of the mutant (lanes $2,4,6,8,10$ ) was reduced $>32$-fold compared with that seen for wild type (lanes 1,3,5,7,9). NodD1-dependent nodA promoter-specific DNA-binding activity was likewise found to be reduced in a B4 mutant strain (data not shown). This indicated that in the homologous system, GroEL expressed from groESLc is needed to achieve full DNA binding by NodD.

Although proteins from cell-free extracts of $R$. meliloti overproducing NodD1 or NodD3 are capable of binding to the nod promoter regions (Fisher et al. 1988), cell-free extracts of $E$. coli carrying the same NodD-overproducing plasmids have failed to show binding previously (R. Fisher, T. Egelhoff, S. Long, unpubl.). We found that overexpression of $E$. coli groESL enhances the nodABC promoter-specific DNA-binding activity of cell-free

Figure 1. Location of two groESL-like sequences in the $R$. meliloti genome, and location of two homologous copies. $(A)$ Cartoon showing the location of the Tn5 in mutant B4 on the $R$. meliloti chromosome (groESLC), and the location of a second homologous copy of groESL on the R. meliloti pSyma. (B) Diagram showing the portion of pSyma that is present in GMI255, but absent from GMI766. (C) Southern blot analysis of $A$. tumefaciens strain A136 carrying pSyma or pSymb shows that the second hybridizing (12-kb BglII) band in $R$. meliloti DNA cotransfers with pSyma, and is present in R. meliloti strain GMI255 which carries a mapped deletion of pSyma. Total bacterial DNA from $R$. meliloti strain Rm1021, A. tumefaciens strain A136, and A136 carrying pSyma or pSymb, and $R$. meliloti deletion strain GMI255 was digested with BgIII, separated by electrophoresis on a $0.7 \%$ agarose gel, blotted and hybridized to a ${ }^{32}$ P-labeled fragment corresponding to "probe L1" in Fig. 2B. The sizes of the two hybridizing BgIII bands in the Rml021 DNA lane is indicated on the right. The $12-\mathrm{kb}$ BglII band which hybridized to the $R$. meliloti groELc probe was present in A136 carrying pSyma, but was absent from A136 carrying pSymb or no R. meliloti megaplasmid. The 7.9-kb BgIII band present in Rm1021 DNA was not present in Al36 carrying pSyma or pSymb, consistent with the chromosomal location determined previously for this fragment. Southern blot hybridizations of EcoRI-digested and HindIII-digested DNA from A. tumefaciens constructs (data not shown) revealed other pSyma and pSymb specific bands that weakly hybridized to our groELc probes, as was observed by Rusanganwa and Gupta (1993) but at slightly different calculated sizes. $(D)$ Southern blot analysis of Rm1021 and of the derivative strain GMI766, which carries a mapped deletion of pSyma shows that the second hybridizing $(6.7-\mathrm{kb} E c \mathrm{RI}, 10-\mathrm{kb} C l a \mathrm{I}, 12-\mathrm{kb} B g I I I)$ band is located in the region of pSyma that is deleted in GMI766, and also shows additional bands hybridizing to R. meliloti groES and groEL probes. Total bacterial DNA was digested with the restriction enzymes indicated, a Southern blot was prepared from a $0.8 \%$ agarose gel and hybridized to "probe S" or "probe L2" (shown in Fig. 2B). 


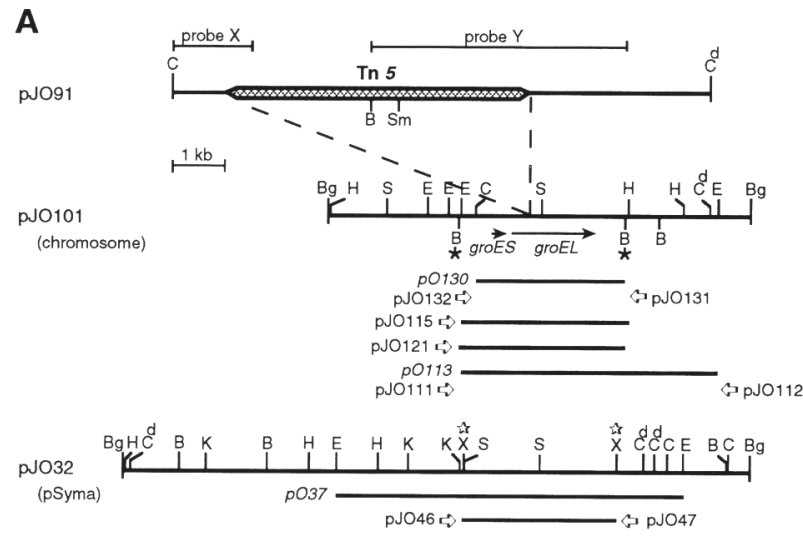

B

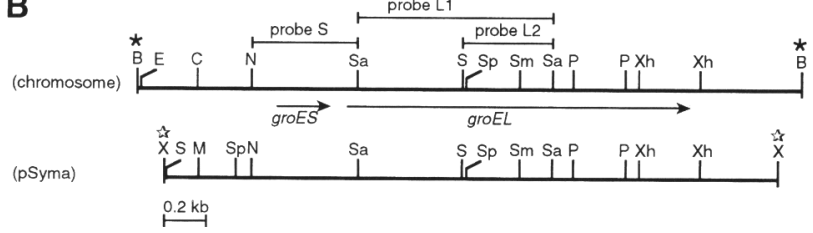

Figure 2. Map of the cloned $R$. meliloti groES and groEL genes. (A) Restriction map of pJO91 which contains the Tn5 and flanking DNA sequences from $R$. meliloti mutant B4. Probes used for Southern blot analysis and for isolating groESL clones from $\mathrm{Rm} 1021$ are indicated above the map. Restriction map of the corresponding region of the $\mathrm{Rm} 1021$ chromosome cloned in pJO101, and subclones used in this study. The locations of the ORFs corresponding to groES and groEL as determined by DNA sequencing are indicated with arrows just below the restriction map; subclones are shown below the restriction map. Restriction map of the region of pSyma cloned in pJO32 which hybridizes to $R$. meliloti groES and groEL probes, and subclones used in this study. Abbreviations: (B) BamHI; (Bg) BglII; (C) ClaI; (E) EcoRI; (H) HindIII; (K) KpnI; (S) SacI; (X) XbaI. C denotes ClaI sites that are not digested in plasmid DNA isolated from $\mathrm{dam}^{+}$ E. coli. For subclones, open arrows indicate the direction of transcription controlled by the lac promoter in the pBluescript or pTG10 vector; names of broad host-range subclones are italicized. (B) A more detailed restriction map of the region encoding the groES and groEL genes. The map of the $3.2-\mathrm{kb} B a m H I$ fragment from pJO101, denoted by asterisks (*) in $A$, is expanded, and the locations of additional restriction sites are shown. Probes used for Southern blot analysis are indicated above the restriction map, and arrows below the map show the location of the groES and groEL ORFs. The map of the 2.9-kb $\mathrm{XbaI}$ fragment from pJO32, denoted by stars in $A$, is also ex. panded and shown in more detail. The two fragments have been positioned so that the restriction sites falling within the groES and groEL coding region are aligned. The DNA sequence is found under GenBank accession number U19726. A purine-rich region located $\sim 8$ nucleotides upstream of the initiation codon for the groES-like sequence, and another located $\sim 9$ nucleotides upstream of the initiation codon for the groEL-like sequence could serve as potential ribosome-binding sequences. 36 nucleotides downstream of the termination codon of the groEL-like sequence is a GC-rich sequence with dyad symmetry and other features of a rho-independent terminator. Abbreviations are as in $A$ and (M) MluI; (N) NheI; (P) PstI; (Sa) SalI; (Sm) SmaI; (Sp) SphI; $(\mathrm{Xh})$ XhoI. extracts of $E$. coli carrying plasmids that overproduce NodD1 or NodD3 (Fig. 4B, lanes 4,9,14). However, the $R$. meliloti groESLc clones were not as effective at conferring this property on $E$. coli (lanes $5,8,12$ ). Overexpressing NodD3 from a high copy number plasmid gave low levels of nod box binding (lane 7), but again the $R$. me-

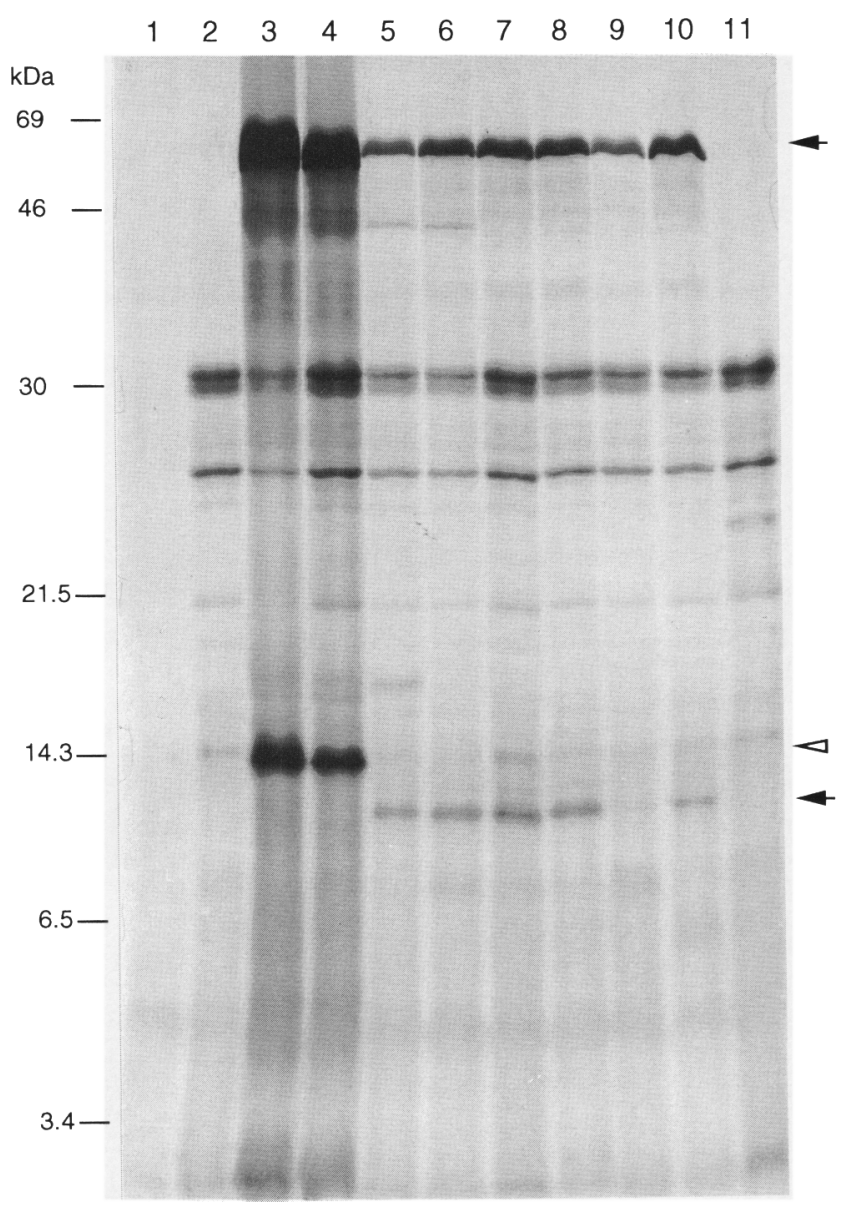

Figure 3. In vitro expression of R. meliloti groESc and groELc protein products. Coupled transcription-translation analysis employed S-30 extracts from $R$. meliloti RCR2011 as described previously (Fisher et al. 1987). An autoradiograph of ${ }^{35} \mathrm{~S}$-labeled proteins separated on a $15 \%$ polyacrylamide-SDS gel displays proteins encoded by vector pBluescript KS + (lane 2) and vector pBluescript $\mathrm{SK}+$ (lane 11). Proteins encoded by clones of $E$. coli groESL, pKS + groESL and pSK + groESL, are shown in lanes 3 and 4 , respectively. Clones of $R$. meliloti groESLc or groESLa were used to direct the synthesis of proteins shown in lanes 5-10 as follows: (lane 5) pJO112; (lane 6) pJO111; (lane 7) pJO131; (lane 8) pJO132; (lane 9) pJO47; (lane 10) pJO46. No template DNA was included in the reaction mixture for lane 1. The positions of both $E$. coli GroEL and R. meliloti GroEL are indicated by the top solid arrow. The position of $E$. coli GroES is indicated by the arrowhead, and the position of $R$. meliloti GroES is indicated by the bottom solid arrow. A novel $17-\mathrm{kD}$ band that appeared in the pJO112 reaction (lane 5) could be attributable to transcription from the lac promoter into the region downstream of the groEL-like ORF, which is present in pJO112, but absent from pJO131. 
Table 3. Complementation of the $B 4$ mutant phenotype

\begin{tabular}{|c|c|c|c|}
\hline \multirow{2}{*}{$\begin{array}{l}\text { Strain } \\
\text { (description) }\end{array}$} & \multirow{2}{*}{$\begin{array}{l}\text { Plasmid } \\
\text { (description) }^{\mathrm{a}}\end{array}$} & \multicolumn{2}{|c|}{ Units $\beta$-galactosidase ${ }^{b}$} \\
\hline & & - luteolin & + luteolin \\
\hline $\begin{array}{l}\mathrm{AL} 110 \\
\quad\left(\operatorname{nod} A B C^{\prime}-{ }^{\prime} l a c Z\right)\end{array}$ & $\begin{array}{l}\text { pRK290 } \\
\text { (vector) }\end{array}$ & 0.7 & 5 \\
\hline $\begin{array}{l}\text { B4T3 } \\
\quad\left(\operatorname{nod} A B C^{\prime}-{ }^{\prime} l a c Z\right)\end{array}$ & pRK290 & 0.6 & 1 \\
\hline AL110 & $\begin{array}{l}\mathrm{pO} 113 \\
\quad(R m \text { groESLc) }\end{array}$ & 0.7 & 5 \\
\hline B4T3 & pOl13 & 0.7 & 5 \\
\hline AL110 & $\begin{array}{l}\mathrm{pO} 37 \\
\quad(R m \text { groESLa })\end{array}$ & 0.7 & 6 \\
\hline B4T3 & pO37 & 0.7 & 5 \\
\hline AL110 & $\begin{array}{l}\mathrm{pO} 43 \\
\quad(E C \text { groESL) }\end{array}$ & 0.8 & 20 \\
\hline B4T3 & pO43 & 0.8 & 16 \\
\hline
\end{tabular}

${ }^{a} E c$ designates $E$. coli genes; $R m$ designates $R$. meliloti genes.

${ }^{\mathrm{b}}$ Cultures were grown in M9-sucrose liquid medium.

liloti groESL had little effect (lane 8 ). The ability of extracts of $E$. coli carrying the nodD1-bearing plasmid pE39 to retard the migration of the nodA promoter fragment was not increased by the inclusion of $3 \mu \mathrm{M}$ luteolin in the binding reaction (lanes 13,15).

The improved nod box binding by NodD in E. coli (Fig. 4B) was not sufficient to confer nod promoter activity in vivo. We made triple constructs of $\mathrm{Lac}^{-} E$. coli containing a nodD plasmid (nodD1 or nodD3), a reporter plasmid with a nod $C^{\prime}-'$ lac $Z$ fusion, and plasmids expressing E. coli groESL or R. meliloti groESLc. None of the resulting strains expressed detectable levels of $\beta$-galactosidase activity. Therefore, although pGroESL was able to enhance nod box DNA binding by $E$. coli overexpressing nodD3 or nodD1, it did not permit transcriptional activation of the nodABC genes in vivo by NodDl or NodD3. Perhaps a further component of the transcription apparatus, such as a $\sigma$ factor or other protein of $R$. meliloti RNA polymerase, also needs to be added to the system.

\section{A $59-k D$ protein that coimmunopurifies with NodD1 is GroEL}

The discovery of a groEL requirement for nod gene ex- pression occurred through a genetic search, and in itself did not indicate whether the mechanism of its effect was indirect or direct. We tested for direct biochemical association of GroEL and NodD1 based on our previous report (Fisher et al. 1988) that a substantially purified preparation of NodDl obtained from immunoaffinity chromatography of $R$. meliloti extracts contained two major proteins: One protein was NodD1, the other was an unidentified $59-\mathrm{kD}$ protein. We prepared a Western blot of this same NodD1 preparation (Fig. 5) and probed it with anti-E. coli GroEL antibodies. We found that the $59-\mathrm{kD}$ protein which coimmunopurified with NodD1 cross-reacts with the anti-GroEL antibodies. In trying to explain the presence of the $59-\mathrm{kD}$ protein in immunopurified NodD1 fractions, Fisher et al. (1988) had suggested that the $59-\mathrm{kD}$ protein independently associated with the immunoaffinity column matrix, because extracts from a $R$. meliloti triple mutant strain containing insertions in nodD1, nodD2, and nodD3 also yielded a small amount of $59-\mathrm{kD}$ protein when passed over the column. However, we have since determined that this nodD mutant strain is leaky for nodD3 expression (Rushing et al. 1991) and produces a NodD1-LacZ fusion protein and possibly a truncated nod 2 gene product. Furthermore, the antibody to NodD1 fails to react with the $59-\mathrm{kD}$ band on a Western blot. Thus, the "triple nodD" mutant probably presented some NodD3 and possibly partial NodDl to the immunoaffinity column, resulting in enough protein to associate specifically with a small amount of GroEL. The biochemical evidence from the column affinity procedure thus suggests a direct binding of GroEL to NodD.

\section{Discussion}

GroEL is a molecular chaperone, a term describing proteins that are important for assembly of other proteins but do not themselves confer steric information nor constitute a part of the mature complex (Ellis and van der Vies 1991; Hendrick and Hartl 1993). GroEL is a bacterial example of the chaperonin-60 class, which also includes proteins in mitochondria, plastids, and eukaryotic cytoplasm (for review, see Ellis and van der Vies 1991). The groEL locus of $E$. coli was originally defined genetically as a host mutation that prevented successful infection by phage. Subsequent work has shown its in-

Table 4. Complementation of E. coli groE mutants

\begin{tabular}{|c|c|c|c|c|}
\hline \multirow[b]{3}{*}{ Plasmid } & \multirow[b]{3}{*}{ Description } & \multicolumn{3}{|c|}{ Relative $\lambda$ plating efficiency (colony formation at $43^{\circ} \mathrm{C}$ ) } \\
\hline & & \multicolumn{3}{|c|}{ E. coli strain $^{\mathrm{a}}$} \\
\hline & & CG2245 (wt) & CG2244 (groES $\left.S^{-}\right)$ & CG2241 (groEL $\left.L^{-}\right)$ \\
\hline pBluescript SK + & vector & $1|+|$ & $<10^{-5}( \pm)$ & $<10^{-5}(-)$ \\
\hline pOF39 & Ec groESL in pBR325 & $1 \nmid+$ & $0.1(+)$ & $0.21+1$ \\
\hline pKS + groESL & Ec groESL in pBluescript (oriented opposite Plac) & $0.91+1$ & $0.6 i+1$ & $0.7 \mid+1$ \\
\hline $\mathrm{pSK}+$ groESL & Es groESL in pBluescript (Plac $\rightarrow$ Ec groESL) & $0.91+1$ & $0.01( \pm 1$ & $<10^{-5}(-)$ \\
\hline pJO115 & $R m$ groESLc in pBluescript $(\mathrm{Plac} \rightarrow R m$ groESLc) & $1.4(+)$ & $0.7( \pm)$ & $0.8( \pm 1$ \\
\hline pJO46 & $R m$ groESLa in pBluescript $(\mathrm{Plac} \rightarrow R m$ groESLa) & $1.5|+|$ & $0.7( \pm)$ & $1.3( \pm)$ \\
\hline
\end{tabular}

a $(+\mid$ Wild-type $(w t)$ colony formation; $( \pm)$ formation of tiny colonies; $(-\mid$ no single colonies formed. 
Ogawa and Long

Table 5. Strains and plasmids

\begin{tabular}{|c|c|c|}
\hline Strain or plasmid & Genotype or relevant characteristics & Source or reference \\
\hline \multicolumn{3}{|c|}{ R. meliloti } \\
\hline AL110 & Rm1021 lac ${ }^{-}$, nod $C^{\prime}-1 a c Z-S p^{r}$ fusion & Lee $\{1988\}$ \\
\hline B4 & AL110::Tn5\#B4 & Lee $(1988)$ \\
\hline B4T1 & Rm1021::Tn5\#B4 (transductant) & this work \\
\hline B4T3 & AL110::Tn5\#B4 (transductant) & this work \\
\hline B4Sp2 & $\mathrm{Rm} 1021: \operatorname{Tn} 5-233 \# \mathrm{~B} 4, \mathrm{Gm}^{\mathrm{r}} \mathrm{Sp}^{\mathrm{r}}$ & this work \\
\hline GMI255 & $2011 \Delta($ fix7064 nod nifHDK) $) 125(\mathrm{Tn} 5) \mathrm{Nal}^{\mathrm{r}}$ & J . Dénarié \\
\hline GMI766 & $2011 \Delta($ nod nif $A) 766 S p^{r}$ & Truchet et al. (1985) \\
\hline JAS301 & Rm1021 nodD3::lacZ 5-1 fusion, $\mathrm{Nm}^{\mathrm{r}}$ & Swanson et al. $\{1993\}$ \\
\hline $\mathrm{Rm} 1021$ & SU47 str-21 & H. Meade \\
\hline $\operatorname{Rm} 5300$ & Rm1021 pRmeSu47b thi-502::Tn5-11 & Finan et al. $\{1986\}$ \\
\hline Rm5321 & Rm1021 pRmeSU47a::Tn5-11 & T. Finan \\
\hline $\mathrm{Rm} 6743$ & Rm1021 $\Omega 615:: \operatorname{Tn} 5-\mathrm{Mob}$ & S. Klein \\
\hline $\operatorname{Rm} 6761$ & 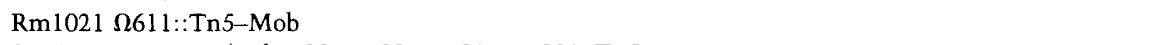 & Klein et al. (1992) \\
\hline Rm6826 & SU47 str-3 spc-1 rif-1 his-39 trp-33 aro-51 ura-501::Tn5 & Klein et al. (1992\} \\
\hline Rm6879 & $\operatorname{Rm} 5000$ recA::Tn5-Tp & S. Klein \\
\hline $\operatorname{Rm} 8002$ & Rm1021 pho-1 & Long et al. (1988) \\
\hline $\mathrm{Rm} 8382$ & Rm8002 fix-382:: TnphoA & Long et al. $\{1988\}$ \\
\hline $\operatorname{Rm} 8620$ & $\mathrm{Rm} 1021 \Delta \operatorname{degP} 65:: \mathrm{Tn} 3 \mathrm{HoKm}$ & Glazebrook et al. (1992) \\
\hline \multicolumn{3}{|c|}{ E. coli } \\
\hline CG2241 & B178zjd::Tn10 groEL44 & C. Georgopoulos \\
\hline CG2244 & B178 zjd::Tn10 groES619 & C. Georgopoulos \\
\hline CG2245 & B178 zjd::Tn $10 \mathrm{groE}^{+}$ & C. Georgopoulos \\
\hline NK5821 & $\mathrm{F}^{-} \Delta\left(\right.$ lac-pro|XIII Nal${ }^{\mathrm{r}} \mathrm{Rif}^{\mathrm{r}}$ arg $^{-} \mathrm{rec} A 56 \mathrm{su}^{-}$ & N. Kleckner \\
\hline Al36 & $\begin{array}{l}\text { A. tumefaciens } \\
\text { C58 derivative, cured of Ti plasmid, Nal' }{ }^{R} \text { if }^{r}\end{array}$ & E. Nester \\
\hline \multicolumn{3}{|c|}{ Phage } \\
\hline N3 & R. meliloti transducing phage & Martin and Long (1984) \\
\hline$\lambda$ & wild type & A. Campbell \\
\hline$\lambda \mathrm{FIX} \mathrm{II-4a}$ & $12 \mathrm{~kb} B g l \mathrm{II}$ fragment containing $R$. meliloti groESLa from Rml021 in $\lambda \mathrm{FIX} \mathrm{II}$ & this work \\
\hline \multicolumn{3}{|c|}{ Plasmids } \\
\hline \multicolumn{3}{|l|}{$\begin{array}{l}\text { pMB1 or } \\
\text { ColE1 replicon }\end{array}$} \\
\hline pBluescript SK + & phagemid vector & Stratagene \\
\hline pBluescript KS + & phagemid vector & Stratagene \\
\hline pADlo & pUC8 with trp promoter and rрo $C$ terminator flanking the polylinker & A. Das \\
\hline pE39 & nodD1 expressed under the control of trp promoter in pAD10 & Egelhoff and Long (1985) \\
\hline pOF39 & E. coli groESL genes in pBR325 & Fayet et al. $\{1986\}$ \\
\hline $\mathrm{pSK}+\mathrm{GroESL}$ & E. coli groESL genes on a $2.2-\mathrm{kb}$ EcoRI-HindIII fragment in pBluescript $\mathrm{SK}+$ & this work \\
\hline pKS + GroESL & E. coli groESL genes oriented opposite lac promoter in pBluescript KS + & this work \\
\hline pRK600 & $\mathrm{Cm}^{\mathrm{r}}$, pRK2013 $\mathrm{Nm}^{\mathrm{r}}: \mathrm{Tn} 9$ helper plasmid & Finan et al. (1986) \\
\hline pRK607 & pRK2013 containing Tn5-233, $\mathrm{Gm}^{\mathrm{r}} \mathrm{Sp}^{\mathrm{r}}$ & De Vos et al. (1986) \\
\hline pJOD3 & nodD 3 expressed under the control of $\operatorname{trp}$ promoter in $\mathrm{pAD} 10$ & this work \\
\hline pJO32 & $12-\mathrm{kb}$ insert from $\lambda$ FIX II-4a cloned as a NotI fragment in pUC 18 & this work \\
\hline pJO46 & R. meliloti groESLa on a $2.9-\mathrm{kb}$ XbaI fragment in pBluescript SK + & this work \\
\hline pJO47 & R. meliloti groESLa on a $2.9-\mathrm{kb} \mathrm{XbaI}$ fragment in pBluescript SK + (oriented opposite lac promoter) & this work \\
\hline pIO91 & $10.5-\mathrm{kb}$ Tn5-containing ClaI fragment from B4T1 in pBluescript SK + & this work \\
\hline pIO101 & product of in vivo excision of $\lambda$ ZAP II-1 & this work \\
\hline pJO111 & R. meliloti groESLc on a $5-\mathrm{kb} E c o \mathrm{RI}$ fragment in pBluescript $\mathrm{SK}+$ & this work \\
\hline pJO112 & R. meliloti groESLc on a $5 \cdot \mathrm{kb} E c o \mathrm{RI}$ fragment in pBluescript $\mathrm{SK}+$ (oriented opposite lac promoter) & this work \\
\hline pJO115 & R. meliloti groESLc on a $3.2-\mathrm{kb}$ Eco RI-HindIII fragment on pBluescript SK + & this work \\
\hline pJO131 & $\begin{array}{l}\text { R. meliloti groESLc on a } 2.9-\mathrm{kb} \text { ClaI-BamHI fragment in pBluescript } \mathrm{SK}+ \\
\text { (oriented opposite lac promoter) }\end{array}$ & this work \\
\hline pJO132 & R. meliloti groESLC on a 2.9 -kb ClaI-BamHI fragment in pBluescript $\mathrm{KS}+$ & this work \\
\hline \multicolumn{3}{|l|}{ p15a replicon } \\
\hline pTG10 & $\mathrm{pACYC}$ 84-based vector with $1 a c$ promoter and multiple cloning site from $\mathrm{pUC} 8, \mathrm{Cm}^{\mathrm{r}}$ & Goloubinoff et al $(1989)$ \\
\hline pGroESL & E. coli groESL cloned into pTG10 & Goloubinoff et al (1989) \\
\hline pJO121 & $\begin{array}{l}\text { R. meliloti groESLc on a } 3.2-\mathrm{kb} \text { BamHI fragment cloned into pTG10, } \\
\text { expressed under the control of lac promoter }\end{array}$ & this work \\
\hline \multicolumn{3}{|l|}{ Broad host range } \\
\hline pRK290 & IncP, $\mathrm{Tc}^{\mathrm{r}}$ & G. Ditta \\
\hline pTE3 & pLAFR 1 containing polylinker flanked by $\operatorname{trp}$ promoter and $r p o C$ terminator & Egelhoff and Long (1985) \\
\hline pCHK57 & PnifA-lacZ fusion & Ditta et al. (1987) \\
\hline $\begin{array}{l}\text { pRK290.720::Tn5- } \\
\text { gus } A 2.774\end{array}$ & nifH::Tn5-gusA fusion & Sharma and Signer (1990) \\
\hline
\end{tabular}


Table 5. (Continued)

\begin{tabular}{|c|c|c|}
\hline Strain or plasmid & Genotype or relevant characteristics & Source or reference \\
\hline pE65 & nodD3 expressed under control of trp promoter in pTE3 & Fisher et al. (1988) \\
\hline pF644 & trp promoter controlling transcription of $\operatorname{lac} Z$ & R. Fisher \\
\hline pJT5 & 20.5-kb region of pRmeSU47a in pLAFR 1 , contains $s y r M$, nodD3, syr $A$, and other genes & Swanson et al (1987) \\
\hline pM142 & nodD3-guSA-Sp $\mathrm{p}^{\mathrm{x}}$ & $\begin{array}{l}\text { Mulligan and Long } \\
\text { (1989) }\end{array}$ \\
\hline pO37 & R. meliloti groESLa on a $6.7-\mathrm{kb}$ EcoRI fragment in pRK290 & this work \\
\hline pO43 & E. coli groESL on a $2.2-\mathrm{kb}$ EcoRI-HindIII fragment in pLAFR3 & this work \\
\hline pO57.33 & $\begin{array}{l}\text { nodD1, nodABC'-'lacZ-Sp }{ }^{\mathrm{r}} \text { from pM57 (Mulligan and Long 1985) on a } 17-\mathrm{kb} \text { EcoRI fragment } \\
\text { in pRK290 }\end{array}$ & this work \\
\hline pO113 & R. meliloti groESLc on a 5-kb EcoRI fragment in pRK290 & this work \\
\hline pO130 & R. meliloti groESLc on a $2.9-\mathrm{kb}$ ClaI-BamHI fragment in pWB5a & this work \\
\hline
\end{tabular}

volvement in stress responses such as heat shock. In $E$. coli, groEL and groES are essential genes (Fayet et al. 1989). Most of the characterized E. coli groEL mutants, such as the groEL44 mutant used in our study, carry missense mutations that limit GroEL function so as not to promote bacteriophage head assembly or not to allow bacterial growth at $43^{\circ} \mathrm{C}$ (Zeilstra-Ryalls et al. 1993). Null mutants that completely lack functional GroEL are not isolable (Fayet et al. 1989). Tests using groESL on recombinant plasmids have provided indirect

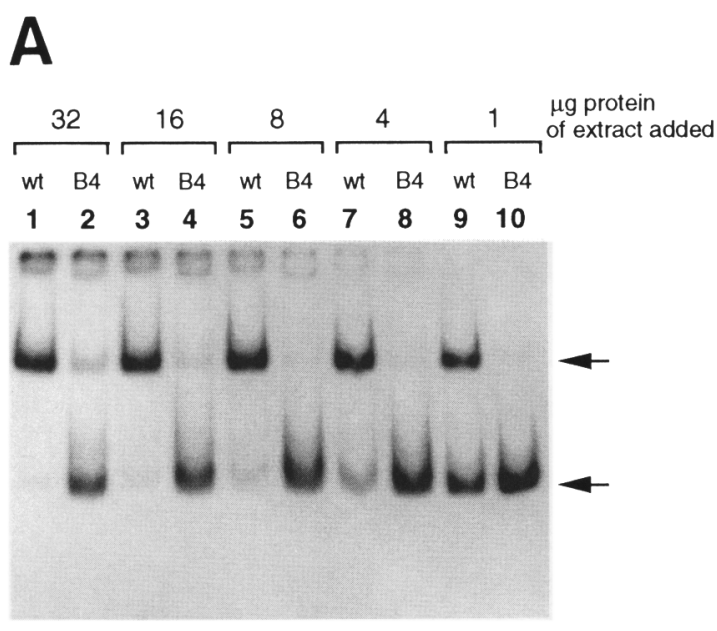

B
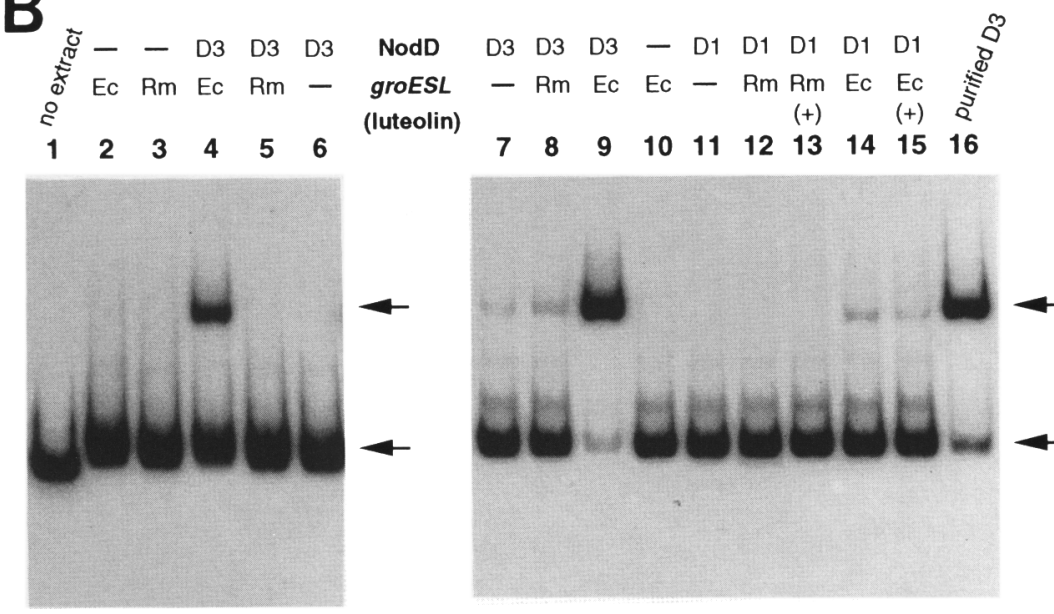

Figure 4. Effect of groESL on NodD-DNA binding. (A) DNA-binding activity of NodD in extracts of wild-type or mutant B4 $R$. meliloti extracts. The nodA nod box promoter was mixed with cell-free extracts from $R$. meliloti strains AL110 or B4T3, both carrying the nodD3-overexpressing plasmid $\mathrm{pE} 65$, and both containing a nod $C^{\prime}-1$ lacZ fusion in pSyma. Extracts were prepared at the same time and under the same conditions. $\beta$-Galactosidase activity was determined for an aliquot of the same culture used for preparing the extracts: AL110 (pE65) gave 350 units and B4T3 (pE65) gave 90 units. The electrophoretically retarded complex is indicated by the top arrow. (B) DNA-binding activity of NodD in extracts of $E$. coli carrying plasmids that overexpress nodD and groESL. Extract protein $(32 \mu \mathrm{g})$ was used in the reaction mixtures for lanes 2-15. The presence of nodD1 or nodD3 on a plasmid is indicated above the lanes, and the presence of $E$. coli groESL or R. meliloti groESLC on a plasmid is also indicated. For lanes 13 and $15,3 \mu \mathrm{M}$, luteolin was included in the binding reaction mixture. For lanes 2-6, to increase expression from the trp promoter on the low copy-number vector, $E$. coli cultures were induced with indole-3acrylic acid as described in Materials and methods. For lanes 7-15, E. coli were grown in $2 \times \mathrm{YT}$ medium, because the trp promoter constructs were on high copy-number vectors that overcame repression of the trp promoter. Note that trp promoter constructs lack the leader peptidecoding region and therefore are not subject to attenuation. E. coli strains used to prepare extracts were NK5821 containing the following plasmids: (lane 2) pTE3 and pKS + groESL; (lane 3) pTE3 and pJO115; (lane 4) pE65 and pKS + groESL; (lane 5) pE65 and pJOl15; (lane 6) pE65 and pBluescript SK + ; (lane 7) pJOD3 and pTG10; (lane 8) pJOD3 and pJO121; (lane 9) pJOD3 and pGroESL; (lane 10) pAD10 and pGroESL; (lane 11) pE39 and pTG10; (lane 12) pE39 and pJO121; (lane 13) pE39 and pJO121; (lane 14) pE39 and pGroESL; (lane 15) pE39 and pGroESL. No extract was included in the binding reaction for lane 1. Instead of extract, 160 ng of partially purified NodD3 (Fisher and Long 1989, 1993) was added to the binding reaction for lane 16. The electrophoretically retarded complex is indicated by the top arrow. 


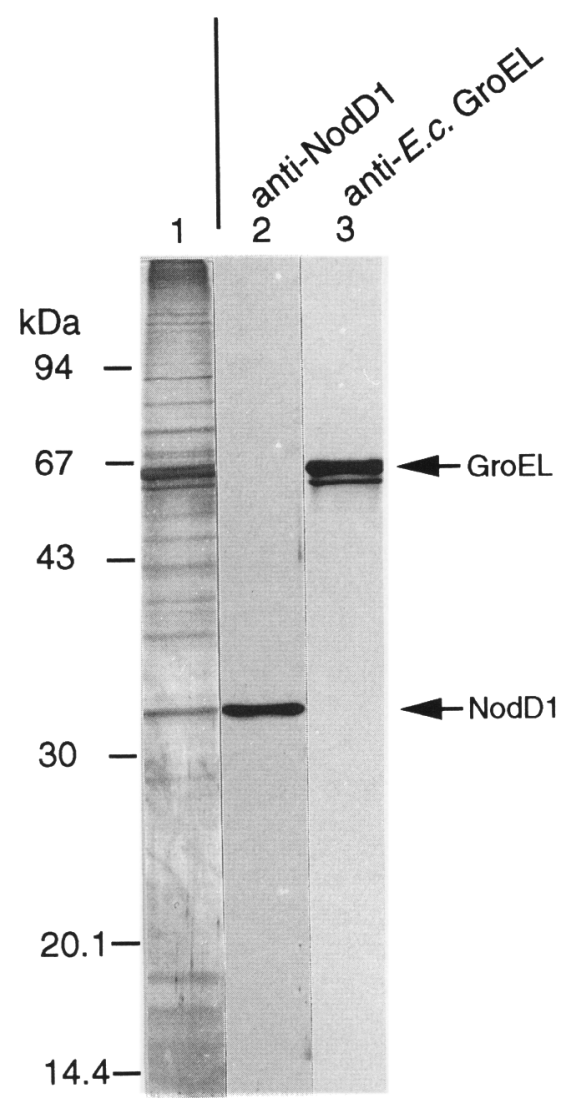

Figure 5. R. meliloti GroEL coimmunopurifies with NodDl. (Lane 1) A silver-stained gel profile of a sample of NodD1 purified by immunoaffinity chromatography (Fisher et al. 1988); (lanes 2,3 ) Western blots of duplicate lanes of the same immunopurified NodDl preparation. The Western blot in lane 2 was probed with anti-NodDl antiserum; the blot in lane 3 was probed with anti-E. coli GroEL antiserum. Sample containing $670 \mathrm{ng}$ of protein was loaded onto each of three lanes of a $12 \%$ polyacrylamide-SDS gel for separation by electrophoresis.

evidence for GroEL (chaperonin-60) involvement in protein assembly in vivo. Overexpression of groEL can suppress temperature-sensitive mutations in numerous proteins and can assure correct formation of foreign proteins overexpressed in E. coli (for review, see Georgopoulos 1992), including heterologous transcription activators (Govezensky et al. 1991; Adar et al. 1992; Dolan and Greenberg 1992).

In vitro studies using well-characterized proteins as substrates have sought to establish the specific mechanism of GroES and GroEL action, along with other molecular chaperone proteins, in binding unfolded or partly folded proteins (for review, see Hendrick and Hartl 1993). The biochemical studies, and observations of the fate of overexpressed genes in heterologous systems, do not specifically address the question of how much GroEL is required in vivo (Horwich et al. 1993). Do some proteins require it more than others? Genetic study in vivo is an important approach to answering this question.

\section{Genetic requirement for GroEL in NodD-activated expression}

Our discovery of a role for GroEL in nod gene expression had its origins in a genetic study similar to the original phage tests: The $R$. meliloti groESL locus emerged in a search for mutations important for gene expression in the nod gene induction system. Specifically, we discovered a transposon Tn5-induced mutant, B4, that decreased transcription resulting from NodD1-luteolinmediated induction. We subsequently showed that this effect extends to NodD3 and to at least one other gene activator of the LysR family, SyrM.

The insertion in the groEL gene resulted in a null mutation. Although this would be lethal in E. coli, in which it has been shown that groESL is essential, the resulting $R$. meliloti B4 mutant was viable, showing only a slightly slower growth rate than wild type. This was explicable by the presence of two functional copies of groESL: one on the chromosome (groESLc) and one on the symbiotic plasmid pSyma (groESLa). The two R. meliloti groEL ORFs are functionally equivalent by two criteria: complementation of the original mutant phenotype, and complementation of the $\lambda$ plating phenotype of an $E$. coli groEL mutant. These functional properties and the high sequence similarity (data not shown) suggest that the two ORFs are functionally redundant. However, we have shown in further work that the two are expressed at different levels, with the chromosomal locus, groESLc, being expressed more highly (J. Ogawa and S.R. Long, in prep.). It appears that other essential cell functions can be sustained by relatively low expression of GroESL proteins. No comprehensive survey of functions was made, but we determined that two processes requiring function of two-component regulatory systems were normal in a B4 mutant strain:dicarboxylic acid transport, which requires $\operatorname{dct} B$ and $\operatorname{dct} D$, and whose expression is necessary for growth on succinate as sole carbon

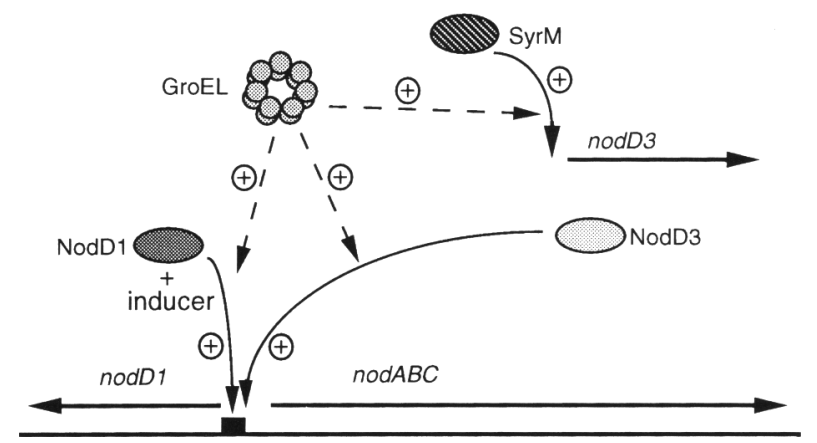

Figure 6. Model of the role of GroEL in $R$. meliloti nod gene regulation. GroEL is required for full NodDl-dependent activation of nodgene expression in the presence of inducer; there is evidence for a physical association between GroEL and NodD1. GroEL is also required for full NodD3-dependent inducer-independent activation of nod gene expression. In addition, GroEL is required for nodD3 expression, which is known to be dependent on the NodD-related protein SyrM. 
source, and nif $A$ expression, which requires fix $L$ and fix $I$. Therefore, it appears that the function of the NodD proteins is unusually sensitive in its need for GroESL and/or requires exceptionally high levels of GroESL.

NodD and SyrM belong to the LysR family of prokaryotic transcriptional activators, a group whose relationship is noted mostly by sequence similarity (Henikoff et al. 1988; Schell 1993). NodD is a regulator first identified in R. meliloti (Egelhoff et al. 1985) and is apparently universal in all Rhizobium, Bradyrhizobium, and Azorhizobium (Kondorosi 1992). From our observations of gene fusion expression, we infer that GroEL is required for the activity of NodD1, NodD3, and SyrM (Fig. 6). This leads us to suggest that GroEL may be required for the activity of all members of the LysR-type activator protein family, whose molecular basis of action has not been established (Schell 1993). A central question about the involvement of GroEL and GroES with NodD will be whether the GroEL requirement is only to assist the folding of NodD itself, which is then fully active, or whether it is required for the correct assembly of NodD with other components of the active transcription apparatus.

The mechanism by which NodD affects gene expression is not known, but it involves binding of NodD to an upstream sequence, the nod box (Fisher and Long 1992; Kondorosi 1992; Schlaman et al. 1992). NodD binds to a 50- to 60-bp segment of DNA along one face of the helix and causes a bend (Fisher and Long 1993). We found that GroEL associates biochemically with NodD and that in the B4 mutant background, the NodD present in the cell binds less well to the nod box. In addition, we observed that an $E$. coli cell overexpressing groEL can produce NodD with a greatly improved ability to bind nod boxes, compared with NodD produced in $E$. coli expressing normal levels of GroEL. This suggests that, at minimum, the GroEL promotes the formation of an active NodD that can bind correctly to its target site. The presence of NodD capable of binding nod boxes did not suffice to permit expression of nod box promoters in E. coli, suggesting that other $R$. meliloti factors necessary for expression are absent from, or different in, E. coli. It is possible that $E$. coli RNA polymerase is not able to interact with NodD and the nod box promoter in a way that results in expression from the promoter. It has been observed previously that some constitutive Rhizobium promoters, such as trp, do not function in $E$. coli because of the failure of the $E$. coli RNA polymerase to recognize the upstream sequence (Bae et al. 1989). Whether the effect of GroEL on promoter-binding ability of NodD sufffices to explain the whole effect of GroEL, will await complete in vitro reconstitution of NodD-induced gene expression using RNA polymerase from $R$. meliloti.

\section{Multiple groEL loci}

Our ability to study the role of GroEL in gene expression was made possible by the multiple, differentially expressed genes of $R$. meliloti. There have been several reports of multiple copies of groEL genes in other bacteria, including Streptomyces albus (Guglielmi et al. 1991;
Mazodier et al. 1991), several species of Mycobacterium (Rinke de Wit et al. 1992; Hughes 1993; Kong et al. 1993), and Synechocystis sp. PCC6803 (Lehel et al. 1993). Purified plastid chaperonin 60 (Rubisco-binding protein) contains approximately equal amounts of two polypeptides (Hemmingsen and Ellis 1986) called $\alpha$ and $\beta$, which are both encoded by nuclear genes, and which show sequence divergence (50\% identity) (Martel et al. 1990; Ellis and van der Vies 1991). The significance of such multiple GroEL loci-for example, differential function, or differential regulation-has not been established in most of these cases.

In the case of $R$. meliloti, there exist other hybridizing bands visible on Southern blots when groEL is used as a probe (Fig. 1, and Rusanganwa and Gupta 1993), although only one of these fragments also shows any hybridization to a groES probe. Whether these hybridizing sequences are functional is unknown; but we have found in other work (J. Ogawa and S.R. Long, in prep.) that a double null mutant in groELc and groELa is apparently not viable, which suggests that no other copies can replace them, either for regulatory or functional reasons.

Our observation (Ogawa 1993) that multiple groEL copies seem to exist in other Rhizobium species and in Bradyrhizobium japonicum, but not in the closely related species A. tumefaciens (see also Fischer et al. 1993; Segal and Ron 1993; Wallington and Lund 1994), may point to a role for the additional copies of groEL in the nodulation process. This is reinforced by the studies of Fischer et al. (1993), who discovered five groEL genes in B. japonicum. Two of the copies $\left(g r o E L_{2}\right.$ and groE $L_{4} \mid$ seem to be expressed constitutively at significant levels; the expression of one copy $\left(g r o E L_{3}\right)$ is induced under anaerobic or symbiotic growth conditions; and the expression of $g r o E L_{1}$ and groE $E L_{5}$ was very low, although the expression of groE $L_{1}$ increased $>25$-fold after a shift in growth temperature from $28^{\circ} \mathrm{C}$ to $39^{\circ} \mathrm{C}$ (Fischer et al. 1993). None of the mutant strains made by interrupting any single $B$. japonicum groEL gene displayed a detectable symbiotic phenotype, and, except for the $\mathrm{groEL}_{4}{ }^{-}$ mutant whose growth in minimal medium under aerobic conditions was impaired, growth of the mutants was not affected (Fischer et al. 1993); this points out at least one major difference in the functional organization of the groEL genes in $B$. japonicum compared with R. meliloti.

Given this discovery of NifA-dependent expression of one groESL in Bradyrhizobium, we were intrigued to see that the root nodules generated by our B4 groELc mutant were $\mathrm{Fix}^{-}$. NifA from Klebsiella pneumoniae has been reported to coimmunoprecipitate with GroEL, and genetic data suggest that $K$. pneumoniae NifA activity in E. coli may be decreased by a mutation in the host groEL (Govezensky et al. 1991). These data suggest a role for GroEL in NifA-related responses. However, we found that NifA-dependent nifH expression was normal in the R. meliloti groELc:: Tn5 mutant; thus it is unlikely that the $\mathrm{Fix}^{-}$phenotype of this mutant is attributable to loss of NifA activity.

On the other hand, Govezensky et al. (1991) also re- 
ported that newly synthesized $K$. pneumoniae NifH, NifD, and NifK proteins transiently associated with GroEL in coimmunoprecipitation experiments of pulsechased cells using anti-GroEL antibodies. If GroELc plays a role in nitrogenase component assembly, this could account for the Fix ${ }^{-}$phenotype of the R. meliloti groELc::Tn5mutant; that is, structural genes such as nifHDK may be expressed at high levels in the mutant, but the protein products may not assemble into functional nitrogenase enzyme. In addition, the groELc::Tn5 mutation may affect the function of any of a number of fix gene products that are required for effective nodulation. Finally, as pointed out by Fischer et al. (1993), GroEL may be involved in the translocation of proteins from endosymbiotic bacteroids out into the peribacteroid space, or in the folding and assembly of host-plant polypeptides imported into bacteroids.

\section{Materials and methods \\ Strains, plasmids, and media}

Strains and plasmids are listed in Table 5. The " $\mathrm{Rm}$ " designation used previously for plasmids containing $R$. meliloti sequences, for example, pRmE65, has been omitted from plasmid names listed here. R. meliloti, Agrobacterium, E. coli, and phage $\lambda$ were grown by standard methods and as described previously (Ogawa et al. 1991; Ogawa 1993).

\section{Genetic techniques}

Transductions using $R$. meliloti phage N3 (Martin and Long 1984) were performed essentially as described (Finan et al. 1984), except that cells were washed once with $0.5 \mathrm{ml}$ of LB following adsorption of phage, and the cell pellet was then resuspended in LB plus $5 \mathrm{mM}$ sodium citrate for plating. Distances between markers were calculated (Martin and Long 1984) based on a phage N3 packaging size of $160 \mathrm{~kb}$ (Finan et al. 1984).

Mobilization of broad host-range plasmids into $R$. meliloti was carried out in triparental matings using the helper plasmid pRK600 to provide mobilization functions in trans. Transposon replacements were performed as described (De Vos et al. 1986). Mapping of antibiotic resistance markers to pSyma or pSymb was done by determining whether the marker cotransferred with either megaplasmid carrying the RK2 origin of transfer in $\operatorname{Tn} 5-\operatorname{Tn} 11$ when conjugated into $\operatorname{Rm} 6879$, as described by Long et al. (1988).

Mapping of unmarked sequences to the symbiotic megaplasmids was done by constructing strains of $A$. tumefaciens A136 into which pSyma or pSymb, marked with Tn5-Tn11, had been mobilized (Finan et al. 1986), followed by isolating DNA from these strains and preparing Southern blots, which were then hybridized with cloned probes. Mobilization of pSymb from $\operatorname{Rm} 5300$ into A136 occurred at very low frequency $\left(\sim 10^{-8}\right.$ per recipient), and to verify the $\mathrm{Al} 36$ (pSymb) construct, $\mathrm{Nal}^{\mathrm{r}}$, $\mathrm{Rif}^{\mathrm{r}}$, $\mathrm{Gm}^{\mathrm{r}}, \mathrm{Sp}^{\mathrm{r}}$ colonies from this mating were screened for resistance to $R$. meliloti phage N3, and DNA from these strains was probed in Southern hybridizations with pSymb-specific insert DNA from clone pJG56A (J. Glazebrook, unpubl.); mobilization of pSyma into Al36 occurred at higher frequencies $\left(>10^{-6}\right)$, and constructs were verified by antibiotic resistance, by screening for phage resistance, and by DNA hybridizations.

Mapping of the Tn5-Tn233 in B4Sp2 was done using approaches described by Klein et al. (1992) and Glazebrook et al.
(1992). The B4Sp2 marker transferred with the highest efficiencies from Tn5-Mob $\Omega 611$ and $\Omega 615$ about equally (Ogawa 1993), indicating that the Tn5 insertion in mutant $\mathrm{B} 4$ lies between trp-33 and pyr-49 on the $R$. meliloti chromosome.

The plating ability of bacteriophage $\lambda$ on $E$. coli hosts was initially determined by the spot titer method: Bacteriophage $\lambda$ lysate was serially diluted in $\lambda$-dil and $5 \mu l$ of several dilutions was spotted onto lawns of appropriate $E$. coli. The efficiency of plating was subsequently confirmed by quantitative titration of the phage with preadsorption.

\section{DNA manipulations}

Total bacterial DNA was isolated from $R$. meliloti as described previously (Swanson et al. 1987). Southern blots were prepared as described previously (Ogawa et al. 1991) or by blotting from agarose gels to Magna NT nylon membrane (Micron Separations, Inc.) in $0.25 \mathrm{~N} \mathrm{NaOH}, 1.5 \mathrm{M} \mathrm{NaCl} .{ }^{32} \mathrm{P}$-Labeled probes were prepared by primer extension using random hexanucleotide primers and gel-purified restriction fragment templates by standard methods. Hybridizations were carried out as described previously (Barnett and Long 1990; Ogawa et al. 1991); final washes were done at $65^{\circ} \mathrm{C}$ unless otherwise noted.

pJOD3 was constructed by cloning a 1.6-kb PstI-EcoRI fragment containing nodD3 from pBGRl (Rushing et al. 1991) into pAD10. pKS + groESL and pSK + groESL were constructed by cloning a 2.2-kb EcoRI-HindIII fragment containing $E$. coli groESL from pOF39 into pBluescript $\mathrm{KS}+$ and pBluescript $\mathrm{SK}+$, respectively. The same $2.2-\mathrm{kb}$ EcoRI-HindIII fragment was cloned into pLAFR3 to make pO43.

\section{Cloning of R. meliloti groESL}

The Tn5-containing region of B4Tl was cloned as a $10.5-\mathrm{kb} C l a \mathrm{I}$ fragment, yielding pIO91 (Ogawa 1993). Bacteriophage $\lambda$ clones of $R$. meliloti groESLc and groESLa were obtained by constructing libraries of size-selected BgIII fragments. The 7.9- and 12-kb BglII fragments hybridizing to probe $\mathrm{X}$ and $\mathrm{Y}$ were cloned into $\lambda$ ZAPII and $\lambda$ FIXII vectors (purchased from Stratagene), yielding $\lambda$ ZAPII- 1 and $\lambda$ FIXII-4a, respectively. The $12-\mathrm{kb}$ insert in $\lambda$ FIXII4a was subsequently recloned into pBluescript SK + , yielding pJO32; in vivo excision of $\lambda$ ZAPII-1 yielded pJO101. Southern blot hybridizations of DNA from B4T1 confirmed that the Tn5 is inserted into the 7.9-kb BgIII fragment cloned as pJOl01.

A faint $12-\mathrm{kb} B g$ III band hybridizing to both groEL and groES probes is visible in the GMI766 Southern blot lanes (Fig. 1D, lanes 6 and 12), even though this strain lacks the strongly hybridizing 12-kb groESLa fragment cloned in pJO32. We isolated a faintly hybridizing clone from the same size-selected $\lambda$ FIXII library from which we isolated $\lambda$ FIXII-4a and verified that the insert faintly hybridized to both a groESc and groELc probe; this clone was not characterized further.

\section{Protein analysis}

Coupled transcription-translation reactions using S-30 extracts from $R$. meliloti RCR2011 or E. coli HB101, and the separation and visualization of protein products, were carried out as described (Fisher et al. 1987). Three micrograms of plasmid DNA purified by $\mathrm{CsCl}$-banding was used as template in each reaction mixture. Western blots with NodA-specific antiserum or NodD1-specific antiserum were prepared and probed as described (Egelhoff and Long 1985; Fisher et al. 1988). Anti-E. coli GroEL antibodies were a gift from G. Lorimer (E.I. DuPont de Nemours and Co.). 


\section{DNA-binding assay}

The ability of proteins in extracts of R. meliloti or E. coli to bind specifically to the nodA promoter was assayed by monitoring the specific shift in electrophoretic gel mobility of a labeled nodA promoter-containing fragment as described (Fisher et al. 1988). The nodA promoter-containing fragment used was the 246-bp EcoRI-HindIII fragment from pF528 (Fisher and Long 1989).

Cell-free extracts of $R$. meliloti and $E$. coli were prepared as described (Fisher et al. 1988). To induce expression from the trp promoter on the low-copy-number vector, E. coli carrying pTE3 or pE65was grown overnight at $30^{\circ} \mathrm{C}$ in $\mathrm{M} 9$ minimal medium supplemented with $0.2 \%$ glycerol, $0.5 \%$ casamino acids, $20 \mu \mathrm{g}$ tryptophan $/ \mathrm{ml}, 40 \mu \mathrm{g}$ arginine $/ \mathrm{ml}, 1 \mu \mathrm{g}$ thiamine $/ \mathrm{ml}$, and appropriate antibiotics, then subcultured into 9 volumes of the same medium without tryptophan, grown for another $3 \mathrm{hr}$, after which indole-3-acrylic acid was added to a final concentration of $10 \mu \mathrm{g} / \mathrm{ml}$ and the cells were grown for an additional $10 \mathrm{hr}$ before being harvested. Other $E$. coli were grown in $2 \times$ YT medium with appropriate antibiotics at $30^{\circ} \mathrm{C}$, and harvested at an $\mathrm{OD}_{600}$ reading of $0.8-1.0$.

\section{Enzyme assays}

$\beta$-Galactosidase assays were carried out as previously described (Mulligan and Long 1985) using DMF stock dilutions of luteolin for $4 \mathrm{hr}$ induction of early log phase cells (Ogawa 1993). $\beta$-Glucuronidase (GUS) assays of nodD3 and syrM fusions were carried out as described (Swanson et al. 1993). GUS assays of the nifHgus $A$ fusion were done using the fluorogenic assay described by Jefferson (1987). One unit of GUS activity produces one nanomole of product per minute at $37^{\circ} \mathrm{C}$ and we have normalized this to the $\mathrm{OD}_{600}$ reading of the bacterial culture. For microaerobic induction of nifA-lac $Z$ and nifH-gus $A$ fusions, the stoppered-tube assay (Ditta et al. 1987) was used and the cultures were assayed after $18 \mathrm{hr}$ of growth in $1 \%$ oxygen; aerobically grown controls were shaken in well-aerated flasks and assayed at an $\mathrm{OD}_{600}$ of $\sim 0.2$.

\section{Assessing symbiotic phenotype}

Nodulation assays were conducted using alfalfa seedlings on agar slants as described previously (Ogawa et al. 1991), except that buffered nodulation medium (Ehrhardt et al. 1992) solidified with 12 grams of Bacto-agar per liter was used. Plant tubes were inoculated with bacteria suspended in water from fresh M9-sucrose plates at a dosage of $10^{6}-10^{7}$ bacteria per plant. To test for strain identity, bacteria were isolated from crushed nodules that had been surface-sterilized with $20 \%$ Clorox as described (Long et al. 1988). Nodules formed late by B4 mutants were not attributable to revertants, as inferred from genetic markers.

The nitrogen-fixing activity of nodulated plants was measured indirectly using the acetylene reduction assay (Turner and Gibson 1980). Four weeks after inoculation, test tubes containing nodulated plants were stoppered and injected with $1 \mathrm{ml}$ of acetylene. Eight hours after the acetylene was added, $1 \mathrm{ml}$ of gas was removed from the stoppered tube and analyzed on a Hewlett Packard 5890A gas chromatograph outfitted with a Porapak $\mathrm{N}$ column. Using the flame-ionization detector, we were able to detect $0.02 \%$ conversion of acetylene to ethylene.

\section{Acknowledgments}

This work was supported by National Institutes of Health (NIH) grant R01-GM60392 to S.R.L. and by an NIH training grant in
Cell and Molecular Biology to Stanford University. We thank A. Lee for providing Tn5-mutated $R$. meliloti strains. We also thank C. Georgopoulos, A. Gatenby, J. Dénarié, J. Glazebrook, G. Walker, A. Ichige, F. Ausubel, and G. Ditta for providing strains and plasmids; G. Lorimer and T. Egelhoff for anti-GroEL, anti-NodD and anti-NodA antibodies; R. Fisher and M. Singer for critical reading of the manuscript; and J. Swanson, R. Fisher, J. Mulligan, B. Rushing, L. Zumstein, and S. Schneider for laboratory strains, plasmids, phage and/or DNA. We are grateful for the advice received from J. Glazebrook on mapping, G. Ditta on microaerobic inductions, R. Fisher on DNA-binding assays, J. Swanson and J. Bodeau on GUS protocols, S. Schneider on phage protocols, D. Ehrhardt on microscopy, M. Yelton on S-30 extracts, M. Barnett on computer analysis, and B. White on IAA inductions. We thank R. Waymouth for use of the gas chromatograph, and $M$. Kesti for assistance.

The publication costs of this article were defrayed in part by payment of page charges. This article must therefore be hereby marked "advertisement" in accordance with 18 USC section 1734 solely to indicate this fact.

\section{References}

Adar, Y.Y., M. Simaan, and S. Ulitzur. 1992. Formation of the LuxR protein in the Vibrio fischeri lux system is controlled by HtpR through the GroESL proteins. I. Bacteriol. 174: 7138-7143.

Bae, Y.M., E. Holmgren, and I.P. Crawford. 1989. Rhizobium meliloti anthranilate synthase gene: Cloning, sequence, and expression in Escherichia coli. J. Bacteriol. 171: 3471-3478.

Barnett, M.J. and S.R. Long. 1990. DNA sequence and translational product of a new nodulation-regulatory locus: SyrM has sequence similarity to NodD proteins. I. Bacteriol. 172: $3695-3700$.

Charles, T.C. and T.M. Finan. 1991. Analysis of a 1600-kilobase Rhizobium meliloti megaplasmid using defined deletions generated in vivo. Genetics 127: 5-20.

David, M., M.-L. Daveran, J. Batut, A. Dedieu, O. Domergue, J. Ghai, C. Hertig, P. Boistard, and D. Kahn. 1988. Cascade regulation of nif gene expression in Rhizobium meliloti. Cell 54: $671-683$.

Dénarié, J. and J. Cullimore. 1993. Lipooligosaccharide nod factors, a new class of signaling molecules mediating recognition and morphogenesis. Cell 74: 951-954.

De Vos, G.F., G.C. Walker, and E.R. Signer. 1986. Genetic manipulations in Rhizobium meliloti utilizing two new transposon Tn5 derivatives. Mol. \& Gen. Genet. 204: 485-491.

Ditta, G., E. Virts, A. Palomares, and C.-H. Kim. 1987. The nifA gene of Rhizobium meliloti is oxygen regulated. J. Bacteriol. 169: 3217-3223.

Dolan, K.M. and E.P. Greenberg. 1992. Evidence that GroEL, not $\sigma^{32}$, is involved in transcription regulation of the Vibrio fischeri luminescence genes in Escherichia coli. J. Bacteriol. 174: 5132-5135.

Downie, J.A. 1994. Signalling strategies for nodulation of legumes by rhizobia. Trends Microbiol. 2: 318-324.

Egelhoff, T.T. and S.R. Long. 1985. Rhizobium meliloti nodulation genes: Identification of nodDABC gene products, purification of nodA protein, and expression of nodA in Rhizobium meliloti. J. Bacteriol. 164: 591-599.

Ehrhardt, D.W., E.M. Atkinson, and S.R. Long. 1992. Depolarization of alfalfa root hair membrane potential by Rhizobium meliloti Nod factors. Science 256: 998-1000.

Ellis, R.J. and S.M. van der Vies. 1991. Molecular chaperones. Annu. Rev. Biochem. 60: 321-347. 
Fayet, O., J.-M. Louarn, and C. Georgopoulos. 1986. Suppression of the Escherichia coli dnaA46 mutation by amplification of the groES and groEL genes. J. Bacteriol. 202: 435-445.

Fayet, O., T. Ziegelhoffer, and C. Georgopoulos. 1989. The groES and groEL heat shock gene products of Escherichia coli are essential for bacterial growth at all temperatures. J. Bacteriol. 171: 1379-1385.

Finan, T.M., E. Hartwieg, K. LeMieux, K. Bergman, G.C. Walker, and E.R. Signer. 1984. General transduction in Rhizobium meliloti. J. Bacteriol. 159: 120-124.

Finan, T.M., B. Kunkel, G.F. De Vos, and E.R. Signer. 1986. Second symbiotic megaplasmid in Rhizobium meliloti carrying exopolysaccharide and thiamine synthesis genes. $I$. Bacteriol. 167: 66-72.

Fischer, H.M., M. Babst, T. Kaspar, G. Acuña, F. Arigoni, and H. Hennecke. 1993. One member of a groESL-like chaperonin multigene family in Bradyrhizobium japonicum is coregulated with symbiotic nitrogen fixation genes. $E M B O J$. 12: 2901-2912.

Fisher, R.F. and S.R. Long. 1989. DNA footprint analysis of the transcriptional activator proteins NodD1 and NodD3 on inducible nod gene promoters. J. Bacteriol. 171: 5492-5502.

. 1992. Rhizobium-plant signal exchange. Nature 357: 655-660.

- 1993. Interactions of NodD at the nod box: NodD binds to two distinct sites on the same face of the helix and induces a bend in the DNA. J. Mol. Biol. 233: 336-348.

Fisher, R.F., J.A. Swanson, J.T. Mulligan, and S.R. Long. 1987. Extended region of nodulation genes in Rhizobium meliloti 1021. II. Nucleotide sequence, transcription start sites and protein products. Genetics 117: 191-201.

Fisher, R.F., T.T. Egelhoff, J.T. Mulligan, and S.R. Long. 1988. Specific binding of proteins from Rhizobium meliloti cellfree extracts containing NodD to DNA sequences upstream of inducible nodulation genes. Genes \& Dev. 2: 282-293.

Geiger, O., T. Ritsema, A.A.N. Van Brussel, T. Tak, A.H.M. Wijfjes, G.V. Bloemberg, and H. Spaink. 1994. Role of rhizobial lipo-oligosaccharides in root nodule formation on leguminous plants. Plant Soil 161: 81-89.

Georgopoulos, C. 1992. The emergence of the chaperone machines. Trends Biochem. Sci. 17: 295-299.

Glazebrook, J., G. Meiri, and G.C. Walker. 1992. Genetic mapping of symbiotic loci on the Rhizobium meliloti chromosome. Mol. Plant Microbe Interact. 5: 223-227.

Goloubinoff, P., A.A. Gatenby, and G.H. Lorimer. 1989. GroE heat-shock proteins promote assembly of foreign prokaryotic ribulose bisphosphate carboxylase oligomers in Escherichia coli. Nature 337: 44-47.

Govezensky, D., T. Greener, G. Segal, and A. Zamir. 1991. Involvement of GroEL in nif gene regulation and nitrogenase assembly. I. Bacteriol. 173: 6339-6346.

Guglielmi, G., P. Mazodier, C.J. Thompson, and J. Davies. 1991. A survey of heat shock response in four Streptomyces species reveals two groEL-like genes and three GroEL-like proteins in Streptomyces albus. J. Bacteriol. 173: 7374-7381.

Hemmingsen, S.M., C. Woolford, S. van der Vies, K. Tilly, D.T. Dennis, C.P. Georgopoulos, R.W. Hendrix, and R.J. Ellis. 1988. Homologous plant and bacterial proteins chaperone oligomeric protein assembly. Nature 333: 330-334.

Hendrick, J.P. and F.-U. Hartl. 1993. Molecular chaperone functions of heat-shock proteins. Annu. Rev. Biochem. 62: 349384.

Henikoff, S., G.W. Haughn, J.M. Calvo, and J.C. Wallace. 1988. A large family of bacterial activator proteins. Proc. Natl. Acad. Sci. 85: 6602-6606.

Horwich, A.L., K.B. Low, W.A. Fenton, I.N. Hirschfield, and K.
Furtak. 1993. Folding in vivo of bacterial cytoplasmic proteins: Role of GroEL. Cell 74: 909-917.

Hughes, A.L. 1993. Contrasting evolutionary rates in the duplicate chaperonin genes of Mycobacterium tuberculosis and M. leprae. Mol. Biol. Evol. 10: 1343-1359.

Jacobs, T.W., T.T. Egelhoff, and S.R. Long. 1985. Physical and genetic map of a Rhizobium meliloti nodulation gene region and nucleotide sequence of nodC. J. Bacteriol. 162: 469-476.

Jefferson, R.A. 1987. Assaying chimeric genes in plants: The GUS gene fusion system. Plant Mol. Biol. Rep. 5: 387-405.

Klein, S., K. Lohman, R. Clover, G.C. Walker, and E.R. Signer. 1992. A directional, high-frequency chromosomal mobilization system for genetic mapping of Rhizobium meliloti. $/$. Bacteriol. 174: 324-326.

Kondorosi, A. 1992. Regulation of nodulation genes in Rhizobia. In Molecular signals in plant microbe communications (ed. D.P.S. Verma), pp. 325-340. CRC Press, Boca Raton, FL.

Kondorosi, E., M. Buire, M. Cren, N. Iyer, B. Hoffman, and A. Kondorosi. 1991. Involvement of the syrM and nodD3 genes of Rhizobium meliloti in nod gene activation and in optimal nodulation of the plant host. 5: 3035-3048.

Kong, T.H., A.R.M. Coates, P.D. Butcher, C.J. Hickman, and T.M. Shinnick. 1993. Mycobacterium tuberculosis expresses two chaperonin 60 homologs. Proc. Natl. Acad. Sci. 90: $2608-2612$.

Lee, A.J. 1988. "Genetic circuits for Rhizobium meliloti nod gene regulation." B.Sc. honors thesis, Stanford University, $\mathrm{CA}$

Lehel, C., D. Los, H. Wada, J. Györgyei, I. Horváth, E. Kovács, N. Murata, and L. Vigh. 1993. A second groEL-like gene, organized in a groESL operon is present in the genome of Synechocystis sp. PCC 6803. I. Biol. Chem. 268: 1799-1804.

Leigh, J.A., E.R. Signer, and G.C. Walker. 1985. Exopolysaccharide-deficient mutants of Rhizobium meliloti that form ineffective nodules. Proc. Natl. Acad. Sci. 82: 6231-6235.

Long, S.R. 1989. Rhizobium-legume nodulation: Life together in the underground. Cell 56: 203-214.

Long, S., S. McCune, and G.C. Walker. 1988. Symbiotic loci of Rhizobium meliloti identified by random TnphoA mutagenesis. I. Bacteriol. 170: 4257-4265.

Martel, R., L.P. Cloney, L.E. Pelcher, and S.M. Hemmingsen. 1990. Unique composition of plastid chaperonin-60: $\alpha$ and $\beta$ polypeptide-encoding genes are highly divergent. Gene 94: 181-187.

Martin, J., M. Mayhew, T. Langer, and F.U. Hartl. 1993. The reaction cycle of GroEL and GroES in chaperonin-assisted protein folding. Nature 366: 228-233.

Martin, M.O. and S.R. Long. 1984. Generalized transduction in Rhizobium meliloti. I. Bacteriol. 159: 125-129.

Mazodier, P., G. Guglielmi, J. Davies, and C.J. Thompson. 1991. Characterization of the groEL-like genes in Streptomyces albus. I. Bacteriol. 173: 7382-7386.

Mulligan, J.T. and S.R. Long. 1985. Induction of Rhizobium meliloti nodC expression by plant exudate requires nodD. Proc. Natl. Acad. Sci. 82: 6609-6613.

. 1989. A family of activator genes regulates expression of Rhizobium meliloti nodulation genes. Genetics 122: 7-18.

Ogawa, J. 1993. "Rhizobium meliloti nod gene regulation: A role for groEL in the activation of nod gene expression." Ph.D. thesis, Stanford University, CA.

Ogawa, J., H.L. Brierley, and S.R. Long. 1991. Analysis of Rhizobium meliloti nodulation mutant WL131: Novel insertion sequence ISRm3 in nodG and altered nodH protein product. I. Bacteriol. 173: 3060-3065.

Parkinson, A. 1993. Signal transduction schemes of bacteria. Cell 73: 857-871. 
Peters, N.K., J.W. Frost, and S.R. Long. 1986. A plant flavone, luteolin, induces expression of Rhizobium meliloti nodulation genes. Science 233: 977-980.

Phillips, D.A. 1992. Flavonoids: plant signals to soil microbes. In Phenolic metabolism in plants (ed. H. Stafford), pp. 201231. Plenum Press, New York.

Rinke de Wit, T.F., S. Bekelie, A. Osland, T.L. Miko, P.W.M. Hermans, D. van Soolingen, J.-W. Drijfhout, R. Schöningh, A.A.M. Janson, and J.E.R. Thole. 1992. Mycobacteria contain two groEL genes: The second Mycobacterium leprae groEL gene is arranged in an operon with groES. Mol. Microbiol. 6: 1995-2007.

Rusanganwa, E. and R.S. Gupta. 1993. Cloning and characterization of multiple groEL chaperonin-encoding genes in Rhizobium meliloti. Gene 126: 67-75.

Rushing, B.G., M.M. Yelton, and S.R. Long. 1991. Genetic and physical analysis of the nodD3 region of Rhizobium meliloti. Nucleic Acids Res. 19: 921-927.

Schell, M. 1993. Molecular biology of the LysR family of transcriptional regulators. Annu. Rev. Microbiol. 47: 597-626.

Schlaman, H., B. Lugtenberg, and R. Okker. 1992. The NodD protein does not bind to the promoters of inducible nodulation genes in extracts of bacteroids of Rhizobium leguminosarum biovar viciae. J. Bacteriol. 174: 6109-6116.

Segal, G. and E.Z. Ron. 1993. Heat shock transcription of the groESL operon of Agrobacterium tumefaciens may involve a hairpin-loop structure. J. Bacteriol. 175: 3083-3088.

Sharma, S.B. and E.R. Signer. 1990. Temporal and spatial regulation of the symbiotic genes of Rhizobium meliloti in planta revealed by transposon Tn5-gusA. Genes \& Dev. 4: 344-356.

Swanson, J.A., J.K. Tu, J. Ogawa, R. Sanga, R.F. Fisher, and S.R. Long. 1987. Extended region of nodulation genes in Rhizobium meliloti 1021. I. Phenotypes of Tn 5 insertion mutants. Genetics 117: 181-189.

Swanson, J.A., J.T. Mulligan, and S.R. Long. 1993. Regulation of syrM and nodD3 in Rhizobium meliloti. Genetics 134: 435444.

Tilly, K. and C. Georgopoulos. 1982. Evidence that the two Escherichia coli groE morphogenetic gene products interact in vivo. I. Bacteriol. 149: 1082-1088.

Tilly, K., H. Murialdo, and C. Georgeopoulos. 1981. Identification of a second $E$. coli gro $E$ gene whose product is necessary for bacteriophage morphogenesis. Proc. Natl. Acad. Sci. 78: 1629-1633.

Truchet, G., F. Debellé, J. Vasse, B. Terzaghi, A.-M. Garnerone, C. Rosenberg, J. Batut, F. Maillet, and J. Dénarié. 1985. Identification of a Rhizobium meliloti pSym2011 region controlling the host specificity of root hair curling and nodulation. J. Bacteriol. 164: 1200-1210.

Turner, G.L. and A.H. Gibson. 1980. Measurement of nitrogen fixation by indirect means. In Methods for evaluating biological nitrogen fixation (ed. F.J. Bergersen), pp. 111-138. John Wiley \& Sons Ltd., Chichester, UK.

Wallington, E.J. and P.A. Lund. 1994. Rhizobium leguminosarum contains multiple chaperonin $(\mathrm{cpn} 60)$ genes. Microbiology 140: 113-122.

Zeilstra-Ryalls, J., O. Fayet, L. Baird, and C. Georgopoulos. 1993. Sequence analysis and phenotypic characterization of groEL mutations that block $\lambda$ and T4 bacteriophage growth. J. Bacteriol. 175: 1134-1143. 


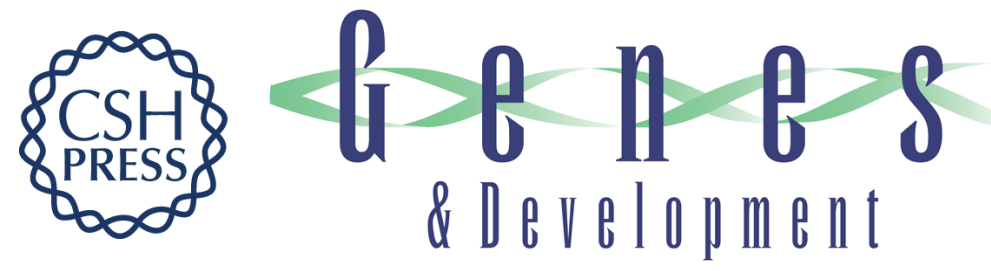

\section{The Rhizobium meliloti groELc locus is required for regulation of early nod genes by the transcription activator NodD.}

J Ogawa and S R Long

Genes Dev. 1995, 9:

Access the most recent version at doi:10.1101/gad.9.6.714

References This article cites 65 articles, 38 of which can be accessed free at:

http://genesdev.cshlp.org/content/9/6/714.full.html\#ref-list-1

License

Email Alerting

Service

Receive free email alerts when new articles cite this article - sign up in the box at the top right corner of the article or click here.

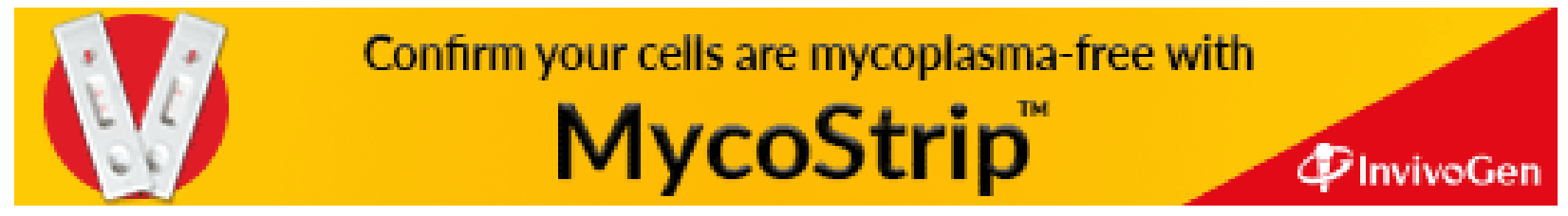

